\title{
DEVELOPMENT OF A ROBUST TRI-CARBIDE FUELED REACTOR FOR MULTI- MEGAWATT SPACE POWER AND PROPULSION APPLICATIONS
}

\section{Final Report}

Contract Number:

DE-FG07-01ID14116

\author{
Principal Investigator: \\ Samim Anghaie \\ Co-Principal Investigator \\ Travis W. Knight
}

Supported by:

Johann Plancher, and Reza Gouw

Innovative Nuclear Space Power and Propulsion Institute (INSPI)

University of Florida

Gainesville, FL 32611-6502

Tel: 352-392-1427, Fax: 352-392-8656 
Development of A Robust Tri-Carbide Fueled Reactor for Multi-megawatt Space Power and Propulsion Applications

\section{TABLE OF CONTENTS}

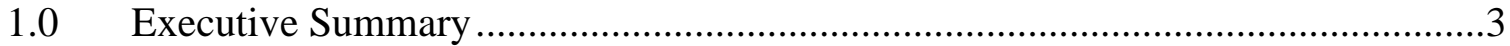

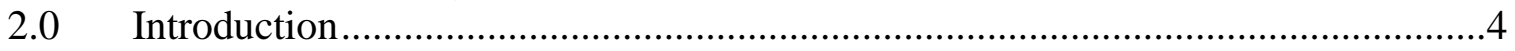

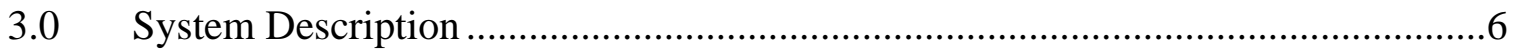

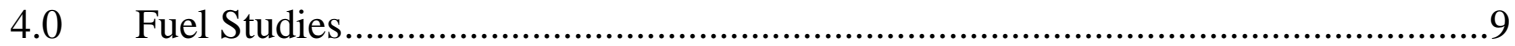

5.0 Nuclear Design Analyses ............................................................................16

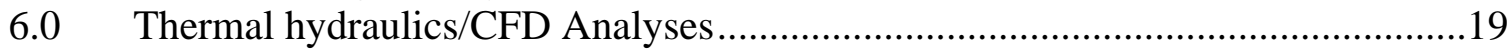

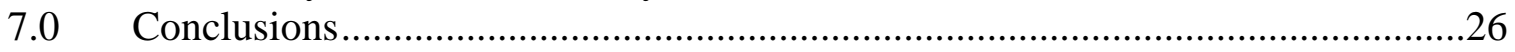

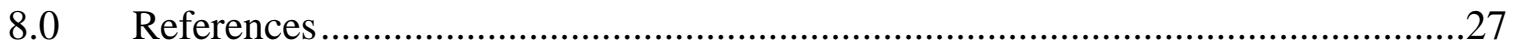


Development of A Robust Tri-Carbide Fueled Reactor for Multi-megawatt Space Power and Propulsion Applications

\subsection{EXECUTIVE SUMMARY}

An innovative reactor core design based on advanced, mixed carbide fuels was analyzed for nuclear space power applications. Solid solution, mixed carbide fuels such as $(\mathrm{U}, \mathrm{Zr}$, $\mathrm{Nb}) \mathrm{c}$ and $(\mathrm{U}, \mathrm{Zr}, \mathrm{Ta}) \mathrm{C}$ offer great promise as an advanced high temperature fuel for space power reactors. This study addressed the difficulties of fabricating these solid solution fuels in traditional space reactor forms and developed methods of processing these high temperature fuels to support the fabrication of the innovative square lattice honeycomb (SLHC) fuel design. The design, in addition to better lending itself to net-shape fabrication with these advanced fuels, also permits the development of an entire class of propulsion systems from 25 to $250 \mathrm{kN}$ thrust with hydrogen exit temperatures of 2800 to $3000 \mathrm{~K}$ for an Isp of 930 to almost 1000 seconds. At the heart of the design is the fabrication of grooved wafers of the solid solution carbide fuel that are interlocked to form a honeycomb structure with the holes providing a channel for the coolant/propellant. The thickness of the individual wafers controls the heat flux and fuel surface and centerline temperatures necessary for a given power/thrust level. Thinner wafers permit higher power densities for higher thrust vehicles while maintaining an acceptable heat flux and fuel surface and centerline temperature. This enables the design of an entire class of reactors with varying power/thrust levels using the same fuel fabrication technology. For a given power/thrust level, it permits the design optimization to achieve the highest performance system while meeting requirements for safety, reliability, long life, and low mass. Fuel processing and fabrication are described and details of the nuclear and thermal hydraulic design and analyses are presented. Nuclear design analyses indicate that a zirconium hydride moderated design is achievable with less than $10 \mathrm{~kg}$ of $93 \%$ enriched U235. A nuclear thermal rocket engine code was developed to model the thermal hydraulic design and performance of the system. With a constant flow area of $30 \%$, a number of designs were analyzed from $40 \mathrm{kN}$ to over 200 $\mathrm{kN}$ thrust levels and an Isp of 930 seconds was calculated for an exit chamber temperature of $2800 \mathrm{~K}$. Detailed computational fluid dynamic analyses using the computer code, FLUENT, were used to validate the results of the model and provide correction factors to adequately represent the square channels of the SLHC design. 
Development of A Robust Tri-Carbide Fueled Reactor for Multi-megawatt Space Power and Propulsion Applications

\subsection{INTRODUCTION}

Solid-core space nuclear reactors could be utilized for a variety of space missions including low-earth-orbit (LEO) to geosynchronous-earth-orbit (GEO) transfers, manned missions to the moon or mars, and orbiter missions to the outer planets. The innovative Square Lattice HoneyComb (SLHC) reactor design allows flexibility for a number of different missions including bimodal nuclear thermal and electric propulsion (BNTEP). Nuclear electric propulsion (NEP) operates by accelerating a propellant by electrothermal, electrostatic, or electromagnetic means using electricity generated from nuclear fission [1]. In nuclear thermal propulsion (NTP), thermal energy is transferred directly from fissioning fuel to the propellant (usually hydrogen), which is then expelled through a nozzle to create thrust. The SLHC design lends itself readily to very efficient NTP mode operation as will be shown below. By employing heat pipes to extract heat from the reactor similar to the SAFE series reactor concept under development [2], power for NEP and/or to support spacecraft systems can be produced by the SLHC reactor. Here the addition of the heat pipes, heat exchanger and power conversion systems become necessary.

Bimodal space nuclear power systems have recently come to the fore in that they allow greater flexibility in optimizing mission trip time and system mass [3]. A key difference between the two modes of propulsion lies in the thrust that is generally attainable and the amount of propellant needed to generate that thrust. This is captured in the equation for specific impulse (Isp) (see Equation 1).

$$
\begin{aligned}
& \mathrm{I}_{\mathrm{sp}}=\mathrm{v}_{\mathrm{g}}=\frac{\mathrm{F}}{\dot{m}} \text { Eq. } 1 \\
& \mathrm{~F}=\text { thrust }(\mathrm{N}) \\
& \dot{m}=\text { propellant mass flow rate }(\mathrm{kg} / \mathrm{s}) \\
& \mathrm{v}_{\mathrm{g}=\mathrm{v}} \text { elocity of propellant relative to rocket }(\mathrm{m} / \mathrm{s})
\end{aligned}
$$

NEP is characterized by high Isp $(10 \mathrm{~s} \mathrm{~km} / \mathrm{s})$ or high propellant velocities but rather small mass flow rates so the resultant thrust is also rather small. Under this lower thrust NEP option the acceleration time is generally very long and consequently the mission time can also be long. However, a key advantage to NEP due to the higher Isp attainable is the reduced amount of propellant mass required for a mission reducing launch costs and/or enabling larger payloads.

With NTP systems, very high thrusts $(100 \mathrm{~s} \mathrm{kN})$ are attainable with corresponding high mass flow rates $(10 \mathrm{~s} \mathrm{~kg} / \mathrm{s})$ so that the Isp is limited to about $10 \mathrm{~km} / \mathrm{s}$ for advanced NTP due to materials limitations for solid core reactor systems. For example, during the Rover/NERVA Programs of the 1960s a specific impulse of $875 \mathrm{~s}$ was demonstrated [4]. By way of reference, the best chemically fueled rockets can theoretically attain an Isp of only about 3300 to $4500 \mathrm{~m} / \mathrm{s}[1,4,5]$. The attraction of BNTEP is the enabling of a rapid departure from orbit using the high thrust afforded by NTP to reduce the mission trip time. The more efficient NEP is then employed away from the gravity field of the Earth or other body reducing the mass of the propellant that must be carried along. 
Development of A Robust Tri-Carbide Fueled Reactor for Multi-megawatt Space Power and Propulsion Applications

The design of the SLHC reactor is based on a solid solution mixed uranium and refractory metal carbide fuel. The motivation for using this advanced fuel can be understood by further examining the Isp for an NTP system. In an NTP system, thrust and hence propulsion is derived from a rocket nozzle by converting the high enthalpy of a propellant stream to kinetic energy. Indeed, what we find is that Isp is proportional to the square root of the propellant temperature divided by its molecular weight (see Equation 2).

$$
\begin{aligned}
& \mathrm{I}_{\mathrm{sp}}=\mathrm{AC}_{\mathrm{f}} \sqrt{\mathrm{T}_{\mathrm{ch}} / \mathrm{M}}=\frac{\mathrm{F}}{\dot{m}} \text { Eq. } 2 \\
& \mathrm{~A}=\text { performance factor related to thermophysical properties of the propellant } \\
& \mathrm{C}_{\mathrm{f}}=\text { thrust coefficient, which is a function of nozzle parameters } \\
& \mathrm{T}_{\mathrm{ch}}=\text { chamber temperature }(\mathrm{K}) \\
& \mathrm{M}=\text { molecular weight of propellant } \\
& \mathrm{F}=\text { thrust }(\mathrm{N}) \\
& \dot{m}=\text { mass flow rate of propellant }(\mathrm{kg} / \mathrm{s})
\end{aligned}
$$

Hence, hydrogen is most often suggested as a propellant and because it can be cryogenically stored at $20 \mathrm{~K}$ instead of the $4 \mathrm{~K}$ needed for helium. The mixed carbide fuels exhibit very high melting temperatures $(>3600 \mathrm{~K})$ and high thermal conductivity, both of which enable very high operating temperatures for higher Isp. This leads to lightweight, very compact, high power cores for space power applications with significant improvement over NERVA and NERVA derivative nuclear thermal propulsion systems.

This report first describes the basic design features of the SLHC system. Next the development of processing and fabrication techniques and testing of the mixed carbide fuel is presented followed by the nuclear design and thermal hydraulic/CFD analyses of the SLHC reactor. 
Development of A Robust Tri-Carbide Fueled Reactor for Multi-megawatt Space Power and Propulsion Applications

\subsection{SYSTEM DESCRIPTIONS}

SLHC fuel is constructed from 93\% enriched uranium-zirconium-niobium carbide $(\mathrm{U}, \mathrm{Zr}$, $\mathrm{Nb}) \mathrm{C}$, which is one of several ternary uranium carbides that are under consideration for this concept. Fabricated in the form of 1 to $2 \mathrm{~mm}$ thick grooved wafers, fuel subassemblies allow hydrogen propellant to flow through the channels formed by the interlocking of these wafers to form a honeycomb structure (see Figure 1). The crosssectional area for flow is $30 \%$.

Five "hockey puck" shaped fuel sub-assemblies are stacked inside a laminar graphitezirconia tube to form a single fuel assembly. The uranium density can be varied between the fuel sub-assemblies axially to shape the power distribution. Fuel sub-assembly diameter and height are $5 \mathrm{~cm}$ and $10 \mathrm{~cm}$, respectively. The laminar tube surrounding the SLHC fuel sub-assemblies is made of $5 \mathrm{~mm}$ thick graphite followed by $5 \mathrm{~mm}$ thick zirconia $\left(\mathrm{ZrO}_{2}\right)$, which insulates the zirconium hydride $\left(\mathrm{ZrH}_{2}\right)$ moderator from the fuel assemblies. The $\mathrm{ZrH}_{2}$ moderator surrounding each assembly is separately cooled by hydrogen propellant. There are 18 fuel assemblies in the core arranged in concentric rings, as shown in Figure 2. The smaller (inner) ring contains six fuel assemblies, and the larger (outer) ring has 12. In the middle of the core, there is a cylindrical Inconel tube that provides structural support for the core. Hydrogen flows through the central channel and expands radially through the moderator pores to a thin annulus region between the core and the radial reflector. This serves to maintain the moderator temperature below $800 \mathrm{~K}$ to prevent its decomposition. The bare core that is surrounded by $10 \mathrm{~cm}$ thick beryllium reflector has a critical diameter and height of $36.8 \mathrm{~cm}$ and $50 \mathrm{~cm}$, respectively. Table 1 presents the SLHC reactor core specifications.

A schematic diagram of the SLHC nuclear rocket engine system configuration is shown in Figure 3. The reactor core presented in Figure 2 is housed inside the reflector within the reactor vessel. The liquid hydrogen propellant is delivered to provide nozzle, reflector, and moderator cooling and to drive the turbo pumps before it is passed through the fuel assemblies in the core. The schematic is not intended to show the actual enginepiping network, but it does show how the engine components and flow rates are interrelated. 
Development of A Robust Tri-Carbide Fueled Reactor for Multi-megawatt Space Power and Propulsion Applications

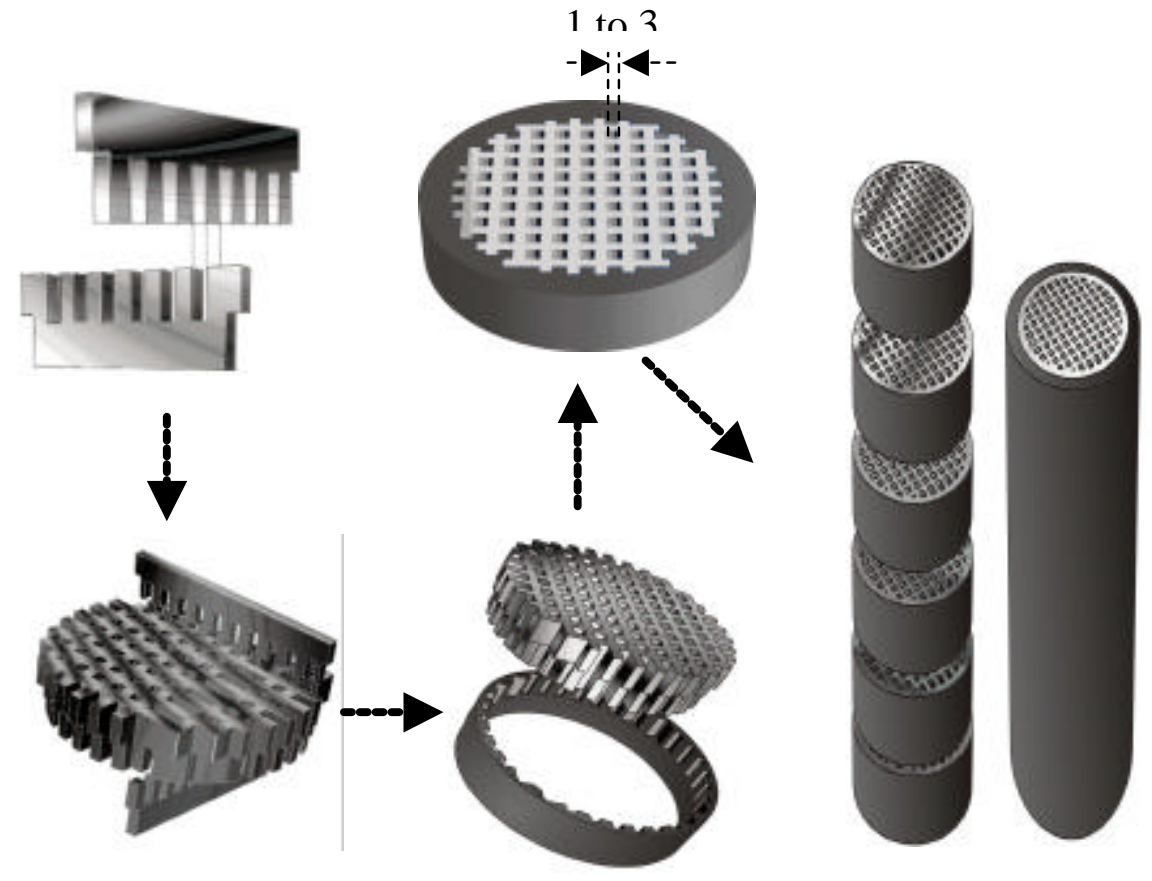

FIGURE 1. Square-Lattice Honeycomb fuel sub-assembly.

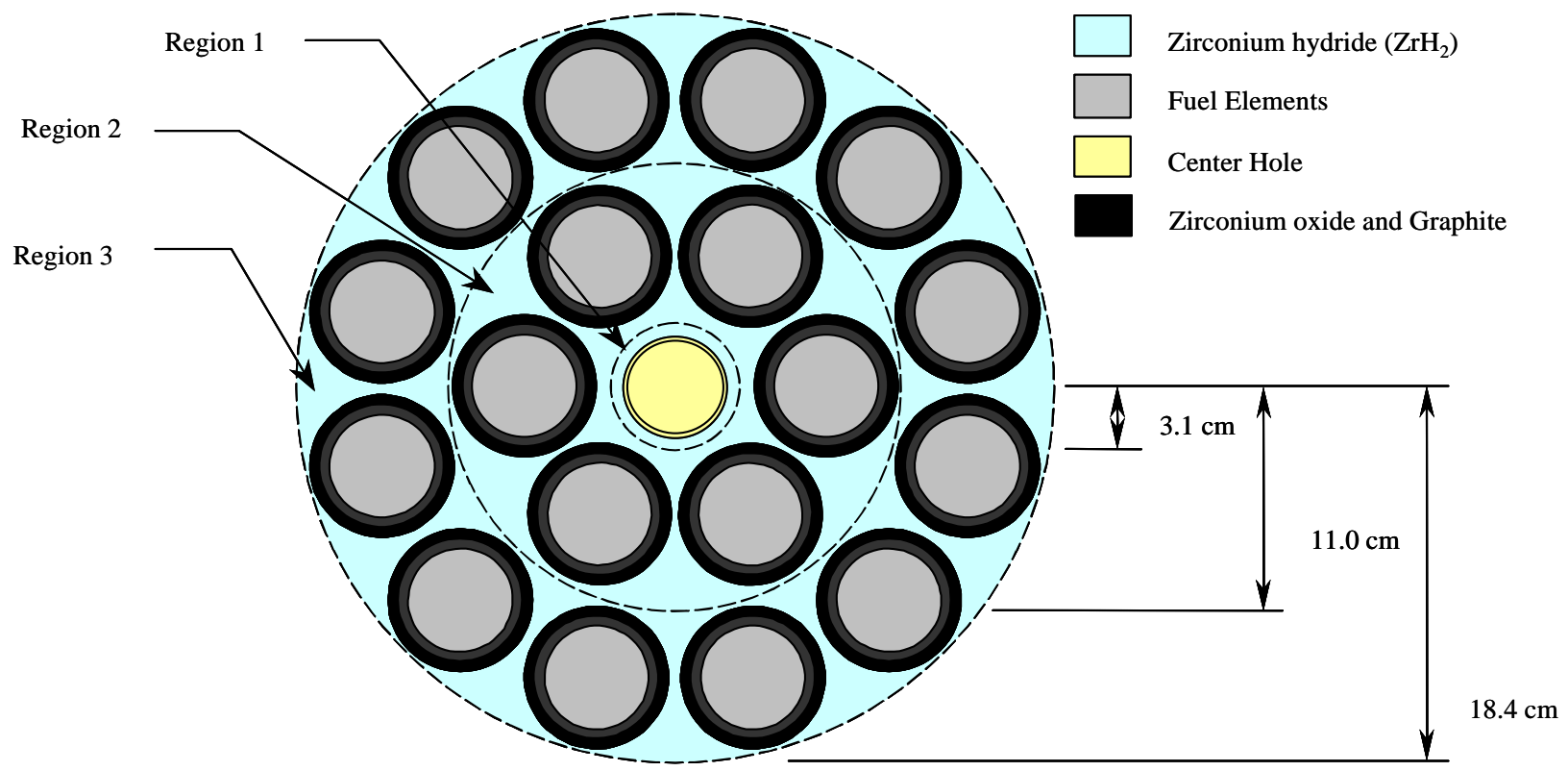

FIGURE 2. Square Lattice Honeycomb core configuration 
Development of A Robust Tri-Carbide Fueled Reactor for Multi-megawatt Space Power and Propulsion Applications
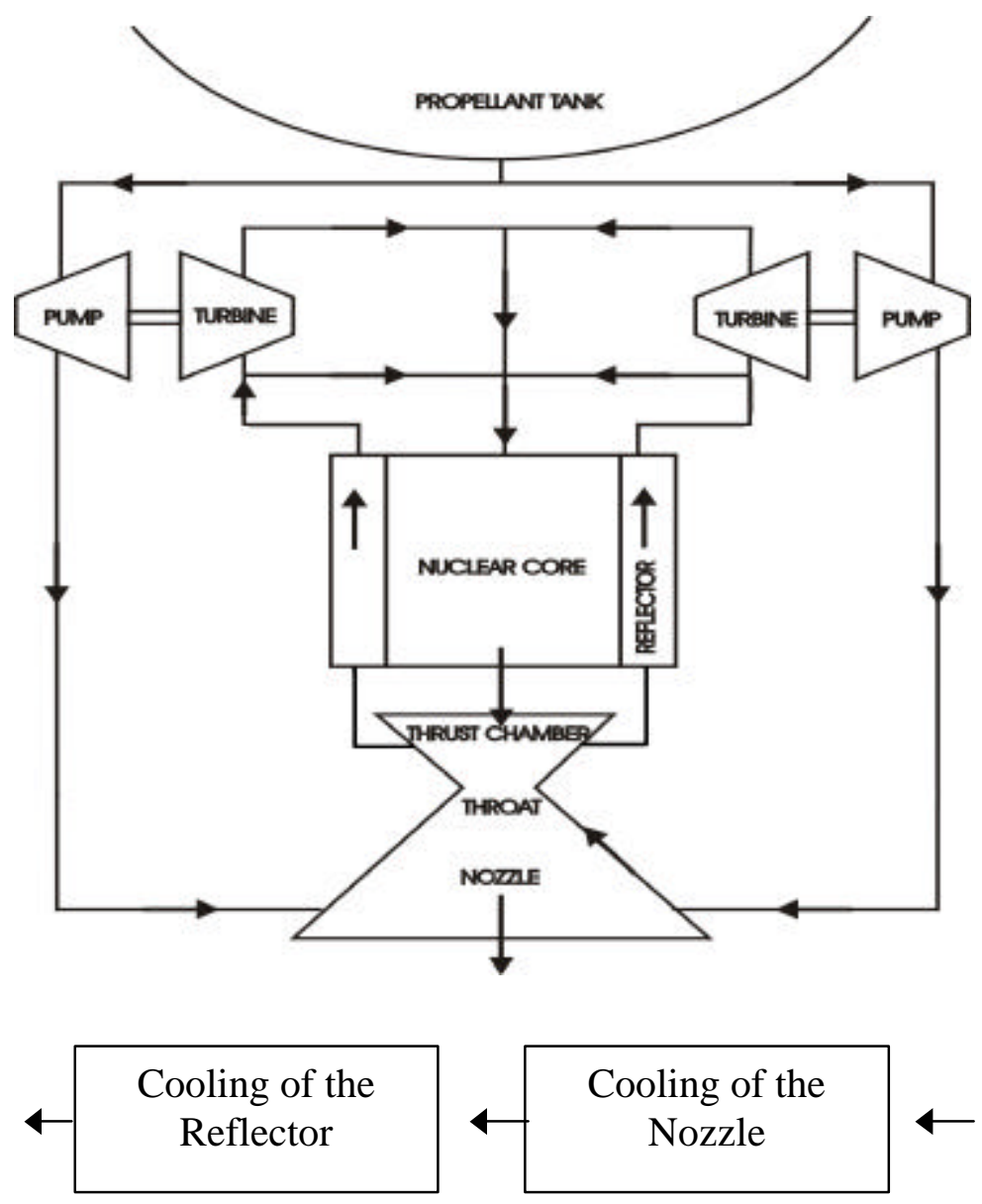

FIGURE 3 - Schematic diagram of the SLHC system (serial cooling configuration). 
Development of A Robust Tri-Carbide Fueled Reactor for Multi-megawatt Space Power and Propulsion Applications

\subsection{FUEL STUDIES}

\subsection{Background}

Solid solution carbide fuels were the last in an evolving series of high performance nuclear fuels tested in the Rover/NERVA programs that operated in the United States from 1955 up until 1973. At their conclusion, insufficient test data were available to judge their performance for NTP applications although they were expected to operate for many hours above $3000 \mathrm{~K}$ [6]. However, fabrication of single-phase, solid-solution carbide fuel elements proved to be a challenge owing to the lack of graphite in the mixture leading to high extrusion pressure and excessive wear on the dies because of the abrasive nature of the carbide particles [6].

Fuel microstructure has been shown to have a large impact on fuel performance, both melting temperature and resistance to hot hydrogen corrosion. The melting temperature of these eutectic compositions, $(\mathrm{U}, \mathrm{Zr}) \mathrm{C}_{\mathrm{x}}+\mathrm{C}$, was noted to be $100 \mathrm{~K}$ to $700 \mathrm{~K}$ lower (depending on the uranium content) than the single-phase, solid solution ( $\mathrm{U}, \mathrm{Zr}) \mathrm{C}$ [7]. During the Rover/NERVA program the $\mathrm{C} / \mathrm{M}$ was kept between 0.88 and 0.95 to maintain a single-phase, solid-solution carbide of (U, Zr)C [6].

Besides their high service temperature and high thermal conductivity, single-phase, solidsolution carbides have a good resistance to corrosion by hot hydrogen compared with earlier Rover/NERVA fuel designs. The study of carbide fuel elements at the end of the Rover/NERVA program was motivated by carbon loss rates in earlier fuel types sufficient to adversely impact neutronic considerations. However, a lack of test data for the solid solution carbide fuel elements meant that their endurance and suitability for NTP applications could not be evaluated.

Owing to the earlier difficulties in processing and fabricating the solid-solution carbide fuels, methods have been developed at the High Temperature Materials Laboratory at INSPI for their processing and fabrication. Because of the high solid-phase solubility of uranium with the refractory metal carbides-namely $\mathrm{ZrC}, \mathrm{NbC}$, and $\mathrm{TaC}$-fuel compositions can be designed from very low uranium fractions (but highly enriched) to very high uranium fractions. For example the Rover/NERVA fuel was 93\% enriched but contained only $0.3 \mathrm{gU} / \mathrm{cc}$. Based on preliminary results of earlier collaboration with the Russian Scientific Research Institute, LUTCH, so-called ternary carbide or tri-carbide compositions of $(\mathrm{U}, \mathrm{Zr}, \mathrm{Nb}) \mathrm{C}$ and $(\mathrm{U}, \mathrm{Zr}, \mathrm{Ta}) \mathrm{C}$ were selected for development. Those preliminary results indicated higher melting temperatures and greater resistance to hot hydrogen corrosion for the tri-carbide compositions than for (U, $\mathrm{Zr}) \mathrm{C}$ alone [8].

\subsection{Fabrication of Tri-carbide Samples}

\subsubsection{Fabrication Methods}

The processing method that was developed involves liquid-phase sintering with UC [9]. A mixture of the constituent refractory carbides with $\mathrm{UH}_{3}$ and graphite are mixed in 
Development of A Robust Tri-Carbide Fueled Reactor for Multi-megawatt Space Power and Propulsion Applications

proportions to yield a $\mathrm{C} / \mathrm{M}$ of 0.92 . In keeping with other studies of high temperature fuels for space power applications, samples with small fractions of uranium were fabricated since the intended fuels for deployment are presumed to be highly enriched ( $\sim 3 \%$ as in Rover/NERVA). This study used depleted uranium in all samples which would exhibit the same thermochemical properties as the enriched fuels. Uranium metal mole fractions of 0.05 and 0.1 were also studied.

Pre-compaction in a stainless steel die at pressures of $50 \mathrm{MPa}$ or greater is used to increase the density of the compact before it is sintered at ultra-high temperatures. The compact is then ejected from the stainless steel die and transferred to a graphite punch and die that acts as a susceptor during sintering in an induction furnace. The early design used a mechanical feedthrough in contact with the graphite punch. To this feedthrough an external load was applied in the form of weights sufficient to provide $3 \mathrm{MPa}$ pressure to samples during sintering. Modifications to the chamber and coil later necessitated the load be applied internal to the chamber. A hot press was designed and constructed in the chamber using a spring loaded punch to contact and press on the samples, while sintering by using induction heating of a graphite susceptor. This method also enabled hot pressing of the samples at pressures of approximately $3 \mathrm{MPa}$ for an added driving force for sintering.

In the initial heat up to $2800 \mathrm{~K}$, the $\mathrm{UH}_{3}$ decomposes above $676 \mathrm{~K}$ evolving hydrogen with the remaining uranium reacting with graphite to form UC. Because the congruent melting point of UC is $2803 \mathrm{~K}$, sintering temperatures exceeding this value were required in order to achieve the enhanced liquid-phase sintering. Rapid densification of the compact was noted when exceeding these temperatures owing to the rearrangement of the refractory carbide particles and the liquid UC filling the open spaces in the microstructure. These temperatures were maintained for several minutes before lowering to 2500 to $2600 \mathrm{~K}$ for solid phase sintering for at least 120 minutes to allow further compaction and the formation of a nearly homogenous solid solution of the mixed carbides. In this manner, small compacts of a few centimeters in size depending on the power and configuration of the induction furnace can be fabricated.

Following sintering, samples were polished and examined by SEM including imaging for compositional contrast using back scattered electrons. Also, small pieces of the processed samples were ground and mounted on slides for analysis by x-ray diffraction. Wafers of each sample weighing about $0.25 \mathrm{~g}$ were cut using a slow speed diamondwafering saw. These wafers were weighed and then combusted in a LECO carbon determinator to measure the amount of $\mathrm{CO}_{2}$ and hence the amount of carbon in each sample.

\subsubsection{Results of Tri-carbide Fuel Fabrication}

Based on the methods outlined in the previous sections, samples of $(\mathrm{U}, \mathrm{Zr}, \mathrm{Nb}) \mathrm{C}$ and $(\mathrm{U}$, $\mathrm{Zr}$, Ta)C were fabricated and a series of tests were conducted to characterize and test the tri-carbide fuels. Various elemental analyses and electron and x-ray probes were used to characterize the microstructure and ensure that the target goals of a single-phase, solid 
Development of A Robust Tri-Carbide Fueled Reactor for Multi-megawatt Space Power and Propulsion Applications

solution, tri-carbide with less than $5 \%$ porosity were produced (see Figure 4). Based on carbon analysis of samples, a $6 \%$ increase in the as fabricated $\mathrm{C} / \mathrm{M}$ over the constituent powders was noted and attributed to carbon pick-up from the graphite die/susceptor during sintering. This must then be allowed for in the fabrication process to ensure an acceptable C/M for a single-phase material.

Samples of the solid solution tri-carbide (U, Zr, Ta)C were processed in the same manner as earlier samples of $(\mathrm{U}, \mathrm{Zr}, \mathrm{Nb}) \mathrm{C}$. This powder metallurgical procedure involved powders of $\mathrm{ZrC}, \mathrm{TaC}, \mathrm{UH}_{3}$, and graphite mixed in proportion to provide compositions with a $\mathrm{C} / \mathrm{M}$ of 0.92 and uranium metal mole fraction of 0.1 and 0.05 . A lower $\mathrm{C} / \mathrm{M}$ ratio of 0.92 was chosen to allow for carbon pickup from the susceptor during the long sintering process at high temperatures, which was demonstrated with earlier samples. This was followed by cold pressing at $50 \mathrm{MPa}$ and liquid phase sintering at temperatures above $2800 \mathrm{~K}$ for times up to 2 hours.

Samples of the tri-carbide, $(\mathrm{U}, \mathrm{Zr}, \mathrm{Ta}) \mathrm{C}$, processed with liquid-phase sintering achieved high theoretical densities of $93 \%$ or greater using this method. Figure 5 illustrates one such sample in the early stages of sintering following the initial heat up to above $2800 \mathrm{~K}$ for liquid phase sintering with UC where it was held for 5 minutes and then a lower temperature of $2600 \mathrm{~K}$ for 20 minutes. The lighter colored areas indicate higher atomic number materials - namely UC. Figure 5 shows the UC filling the grain boundaries and previously open spaces in the microstructure following liquid-phase sintering. In this manner, a well consolidated sample is achieved in a short amount of time and continued sintering at lower temperatures of 2500 to $2600 \mathrm{~K}$ for times up to three hours produced homogenous solid solution mixed carbides of $(\mathrm{U}, \mathrm{Zr}, \mathrm{Ta}) \mathrm{C}$.

X-ray diffraction of the samples showed the $(\mathrm{U}, \mathrm{Zr}$, Ta)C samples processed with a lower initial $\mathrm{C} / \mathrm{M}$ ratio of less than 0.92 to indeed be a solid solution of the tri-carbides (see Figure 6). However, some early samples processed from constituent powders mixed to the desired $\mathrm{C} / \mathrm{M}$ ratio of 0.95 did exhibit additional phases of $\mathrm{UC}_{2}$ and graphite (see Figures 7 and 8). The larger fraction of carbon in the as mixed compact and due to additional carbon pickup from the die walls during sintering is the likely cause of the additional phases of $\mathrm{UC}_{2}$ and graphite observed in Figures 7 and 8 . Carbon measurements of $(\mathrm{U}, \mathrm{Zr}$, Ta)C samples indicated increases of $\mathrm{C} / \mathrm{M}$ of $4 \%$ to $7 \%$ following sintering over the original as mixed compact ratio. The larger increases where exhibited for samples sintered for longer times of 200 minutes or more which is in agreement with expected results since longer times for carbon diffusion from the susceptor wall is permitted. 
Development of A Robust Tri-Carbide Fueled Reactor for Multi-megawatt Space Power and Propulsion Applications

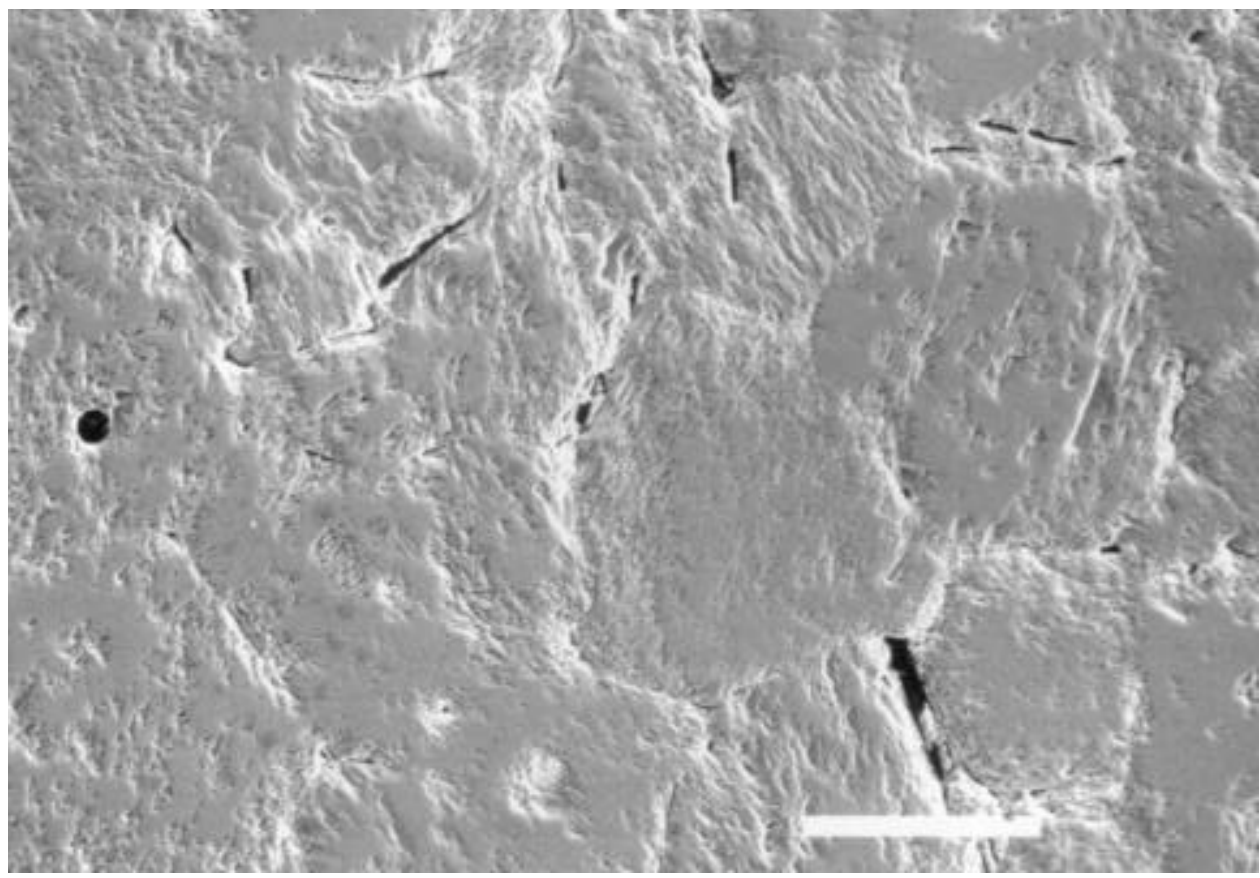

a. SEM

$100 \mu \mathrm{m}$

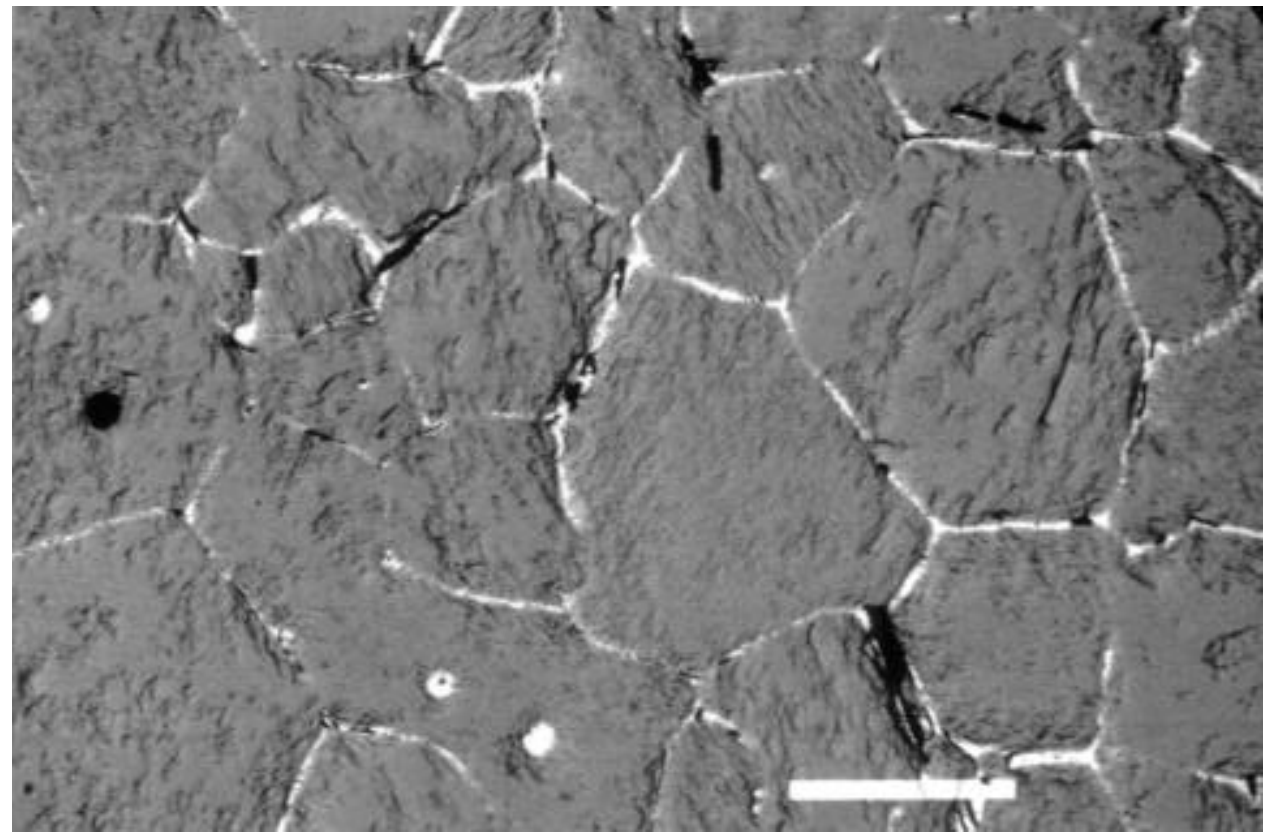

b. SEM with compositional contrast

$100 \mu \mathrm{m}$

FIGURE 4. Tri-Carbide, $\left(\mathrm{U}_{0.1}, \mathrm{Zr}_{0.77}, \mathrm{Nb}_{0.13}\right) \mathrm{C}_{0.95}$ Sintered for $4 \mathrm{Min}$. at $\geq 2800 \mathrm{~K}$ and 128 Min. at $\geq 2500 \mathrm{~K}$. 
Development of A Robust Tri-Carbide Fueled Reactor for Multi-megawatt Space Power and Propulsion Applications

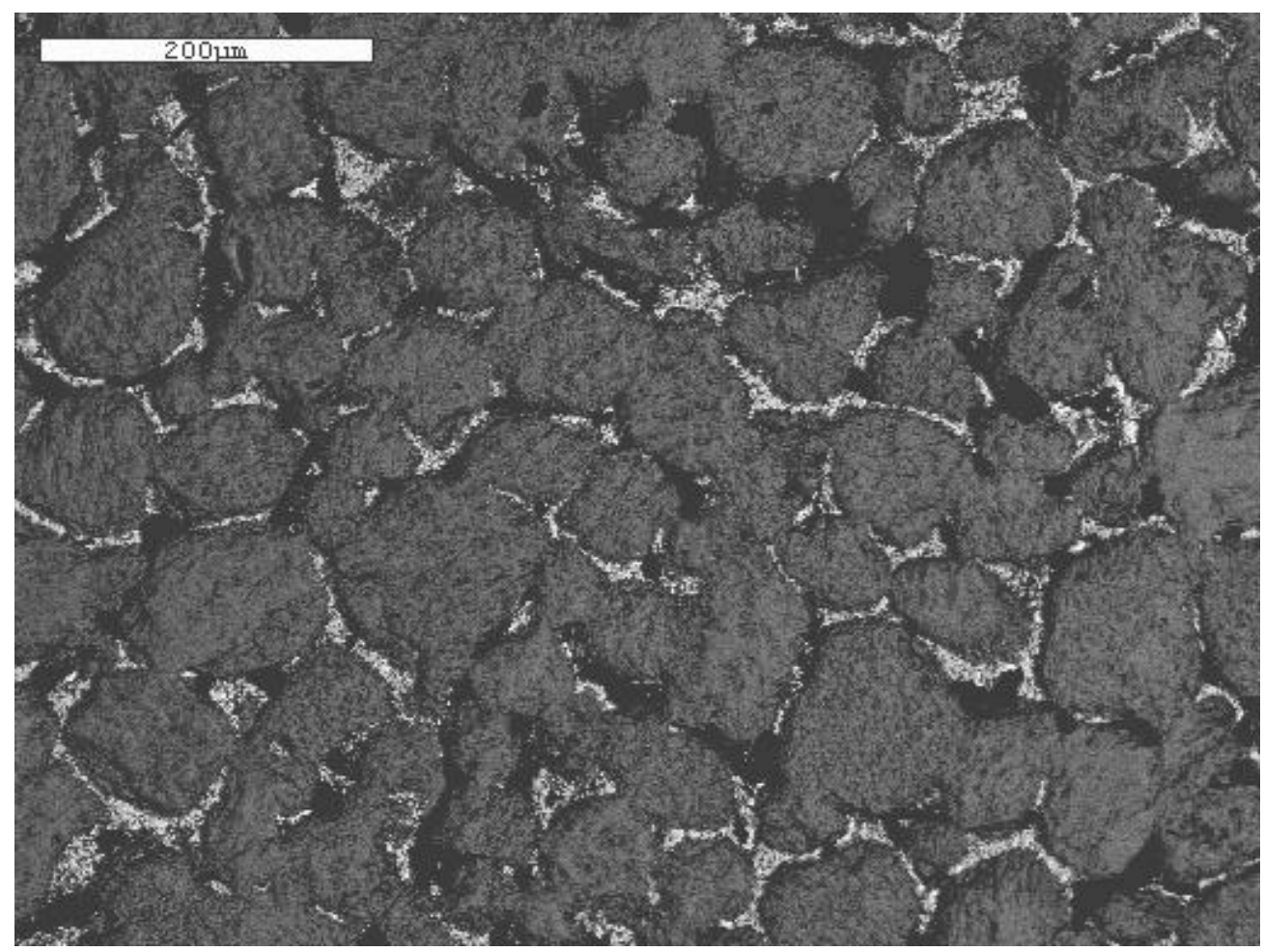

FIGURE 5. Backscattered electron image of ( $\mathrm{U}, \mathrm{Zr}$, Ta)C sample during early stages of processing after $5 \mathrm{~min}$. above $2800 \mathrm{~K}$ and $20 \mathrm{~min}$. above $2600 \mathrm{~K}$.

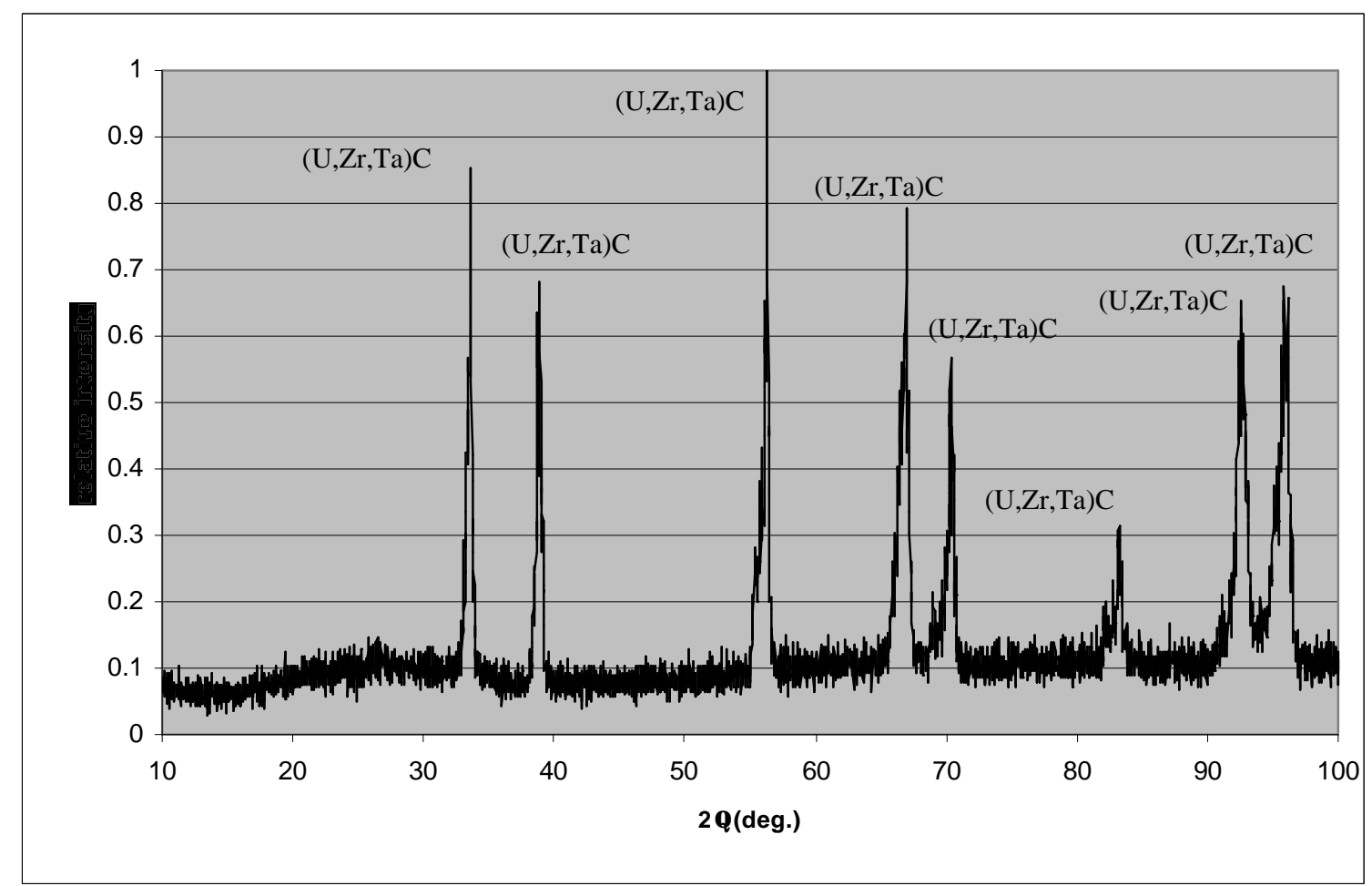

FIGURE 6. Representative $x$-ray diffraction profile for single phase solid solution (U, $\mathrm{Zr}, \mathrm{Ta}) \mathrm{C}$. 
Development of A Robust Tri-Carbide Fueled Reactor for Multi-megawatt Space Power and Propulsion Applications

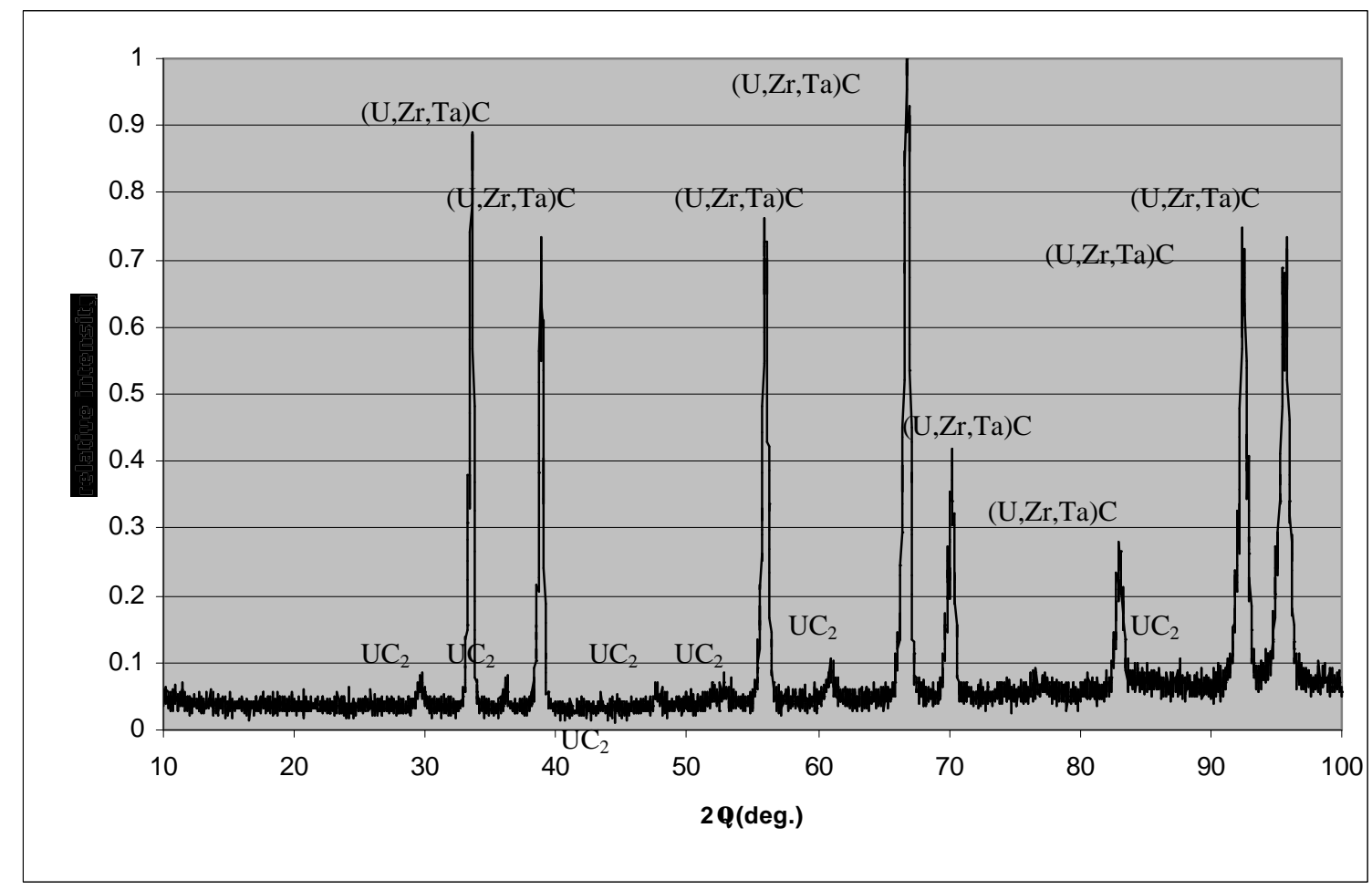

FIGURE 7. Representative $\mathrm{x}$-ray diffraction profile of $(\mathrm{U}, \mathrm{Zr}$, $\mathrm{Ta}) \mathrm{C}$ samples containing and additional $\mathrm{UC}_{2}$ phase.

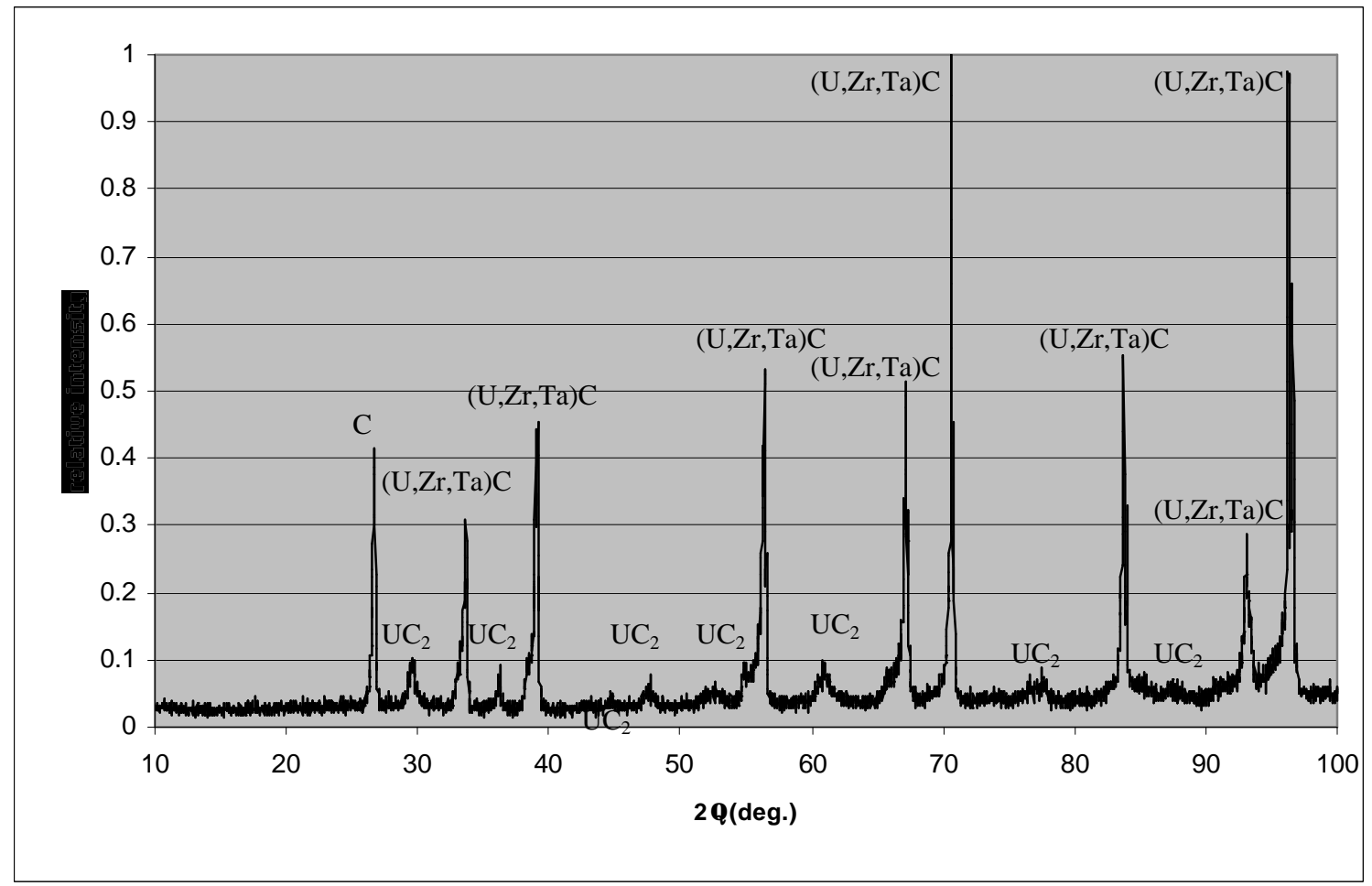

FIGURE 8. Representative $\mathrm{x}$-ray diffraction profile of $(\mathrm{U}, \mathrm{Zr}, \mathrm{Ta}) \mathrm{C}$ samples containing $\mathrm{UC}_{2}$ and graphite phases. 
Development of A Robust Tri-Carbide Fueled Reactor for Multi-megawatt Space Power and Propulsion Applications

\subsection{Hot Hydrogen Testing of Samples}

Because the most extreme conditions the tri-carbide fuels are expected to face would be during operation in NTP mode, a series of thermo-chemical tests in flowing hot hydrogen have been initiated. Results of these tests are shown in Figure 9. This test involved three different $\left(\mathrm{U}_{0.1}, \mathrm{Zr}_{0.45}, \mathrm{Nb}_{0.45}\right) \mathrm{C}$ pellets $0.635 \mathrm{~cm}$ in diameter stacked on top of a tungsten pedestal inside a tungsten tube. Hydrogen was allowed to flow through the tube at a rate of $2 \mathrm{~g} / \mathrm{min}$. The tube acted as a susceptor to heat the hydrogen gas by radiation before passing over the samples, which were also heated, by the susceptor. The samples were heated to $2500 \mathrm{~K}$, which is in the critical temperature range where the hot hydrogen can still react with the carbon and thereby corrode the samples. At temperatures above 2800 $\mathrm{K}$, the hydrocarbons are unstable and the dominant loss mechanism is due to vaporization from the surface of the fuel [10]. These results indicate only small mass losses of about $1 \%$ for four hours operation. Design of SLHC fuel assemblies must factor in these losses that can be expected to occur while operating in NTP mode. Fortunately, the burn time in this mode is relatively short, about one to two hours, to enable rapid departure from orbit.

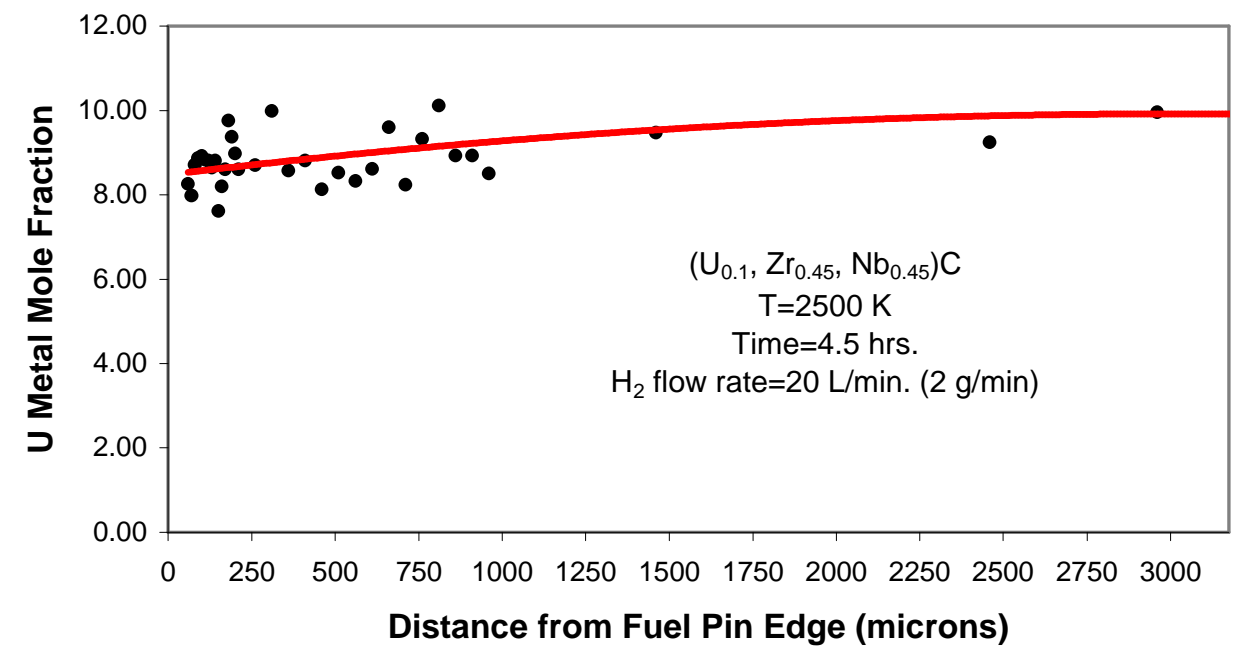

FIGURE 9. Performance of solid solution tri-carbide nuclear fuels exposed to hot hydrogen. 
Development of A Robust Tri-Carbide Fueled Reactor for Multi-megawatt Space Power and Propulsion Applications

\subsection{NUCLEAR DESIGN ANALYSES}

Two methods of calculation were used to analyze the nuclear design characteristics of the SLHC core, a diffusion theory method using the VENTURE computer code and a Monte Carlo method using the MCNP 4B [11] computer code system [12]. Group constants for VENTURE were obtained from the COMBINE code by using a B-1 approximation to the neutron transport equation. COMBINE is a FORTRAN 77 computer code for the generation of spectrum-averaged multigroup neutron cross-section data suitable for use in diffusion and transport theory reactor design analysis [13]. VENTURE is a PC based version of the BOLD VENTURE system of connected codes or modules used to analyze the core of a nuclear reactor by applying multigroup diffusion theory. The code system can analyze one, two, or three dimensions in various geometries. Variable dimensioning is used throughout the codes, which allows for any number of energy groups and mesh points, with the limitation that the problem fits into the core memory [14].

Three radial regions are defined to perform the analysis of the SLHC core, as shown in Figure 2. Five different unit cells for each region were used to homogenize the fuel and moderator in the SLHC fuel element. These unit cells correspond to the five different axial temperature zones and five axial fuel compositions with varying uranium density. Table 2 presents the temperature zones and axial uranium density variations of the SLHC core. For each unit cell, a COMBINE run was performed to obtain the average macroscopic and microscopic cross-section of the core. These cross-sections were used to perform criticality calculations using VENTURE. The buckling used for the unit cell was calculated based on the geometric buckling. Resonance integrals were calculated using the Nordheim method with fuel-moderator homogeneous approximation. Temperature variations in the core are accommodated by the treatments of the Doppler broadening in the code. The average microscopic cross-section of the beryllium in the reflector is calculated by incorporating a very small concentration of this material in every region in fuel-moderator unit cells and requesting COMBINE to output those values for use in core criticality calculations using VENTURE.

\subsection{Results of Nuclear Design Analysis}

Figure 10 presents the energy dependent neutron flux averaged over the core volume for SLHC reactor. The high concentration of neutrons in low energy regions indicates that the SLHC matches closely the spectral characteristics of thermal reactor systems. Table 3 includes the relative fraction of neutrons that induced fission in the SLHC. The spectral characteristics of the relative fraction of neutrons that induced fission reaction is used to characterize the spectral nature of SLHC reactor cores. As is indicated in Table 3, neutrons with average energies below $0.2 \mathrm{eV}$ generate about $78 \%$ of the system power (or nearly $78 \%$ of fissions). Results presented in Figure 10 and Table 3 indicate that despite the small size, the SLHC provides sufficient moderation for the fission neutrons.

The compactness of the SLHC is mainly attributed to the zirconium hydride moderator as well as to the use of axial and radial beryllium reflectors. Zirconium hydride has a high neutron scattering peak in the thermal energy range. The COMBINE neutron cross- 
Development of A Robust Tri-Carbide Fueled Reactor for Multi-megawatt Space Power and Propulsion Applications

section library only includes one temperature for zirconium hydride. An analysis was performed to determine the temperature coefficient for the zirconium hydride peak by using MCNP4B. The zirconium hydride temperature coefficient was determined by varying the zirconium hydride temperature while keeping the temperatures of other components of the unit cell constant. The result obtained from this analysis indicated that the effect of zirconium hydride resonance peak in the range of operating system temperatures is less than $0.1 \%$.

The value of axial and radial power peaking factors are 2.10 and 1.35 respectively. An important safety concern for the nuclear rocket systems is the potential criticality related accident due to a hypothetical reentry accident that results in water submersion. A hypothetical water submersion accident scenario is analyzed for the SLHC reactor system. The analysis is performed at room temperature because water has the highest density at this temperature. For this analysis, the hydrogen holes in SLHC fuel are filled with water, and the reactor is surrounded by water. Using the MCNP 4B model for the core, the effective multiplication factor for the water submersion accident for the SLHC system without the insertion of safety control rod is determined to be 1.3513. However, after the insertion of boron carbide into the central reactor duct the effective multiplication factor drops to less than one.

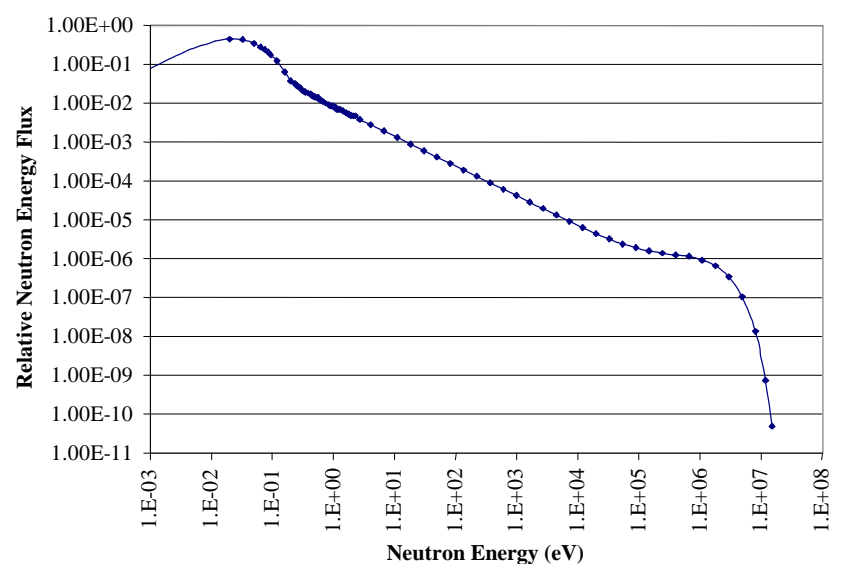

FIGURE 10. Square-Lattice Honeycomb neutron energy spectrum obtained from COMBINE. 
Development of A Robust Tri-Carbide Fueled Reactor for Multi-megawatt Space Power and Propulsion Applications

TABLE I. Square Lattice Honeycomb reactor specifications.

\begin{tabular}{lc}
\hline Properties & Values \\
\hline Bare Core Diameter $(\mathrm{cm})$ & 36.8 \\
Core Height $(\mathrm{cm})$ & 50 \\
Radial reflector thickness $(\mathrm{cm})$ & 10 \\
Top axial reflector thickness $(\mathrm{cm})$ & 10 \\
Fuel Material & $(\mathrm{U}, \mathrm{Zr}, \mathrm{Nb}) \mathrm{C}$ \\
Fuel enrichment $(\%)$ & 93 \\
Uranium density $\left(\mathrm{g} / \mathrm{cm}^{3}\right)$ & $0.4-1.0$ \\
Amount of 235U $(\mathrm{kg})$ & 9.2 \\
Propellant & $\mathrm{H}_{2}$ \\
\hline
\end{tabular}

TABLE II. Square-Lattice Honeycomb axial temperature zones and uranium density variations for unit cell calculations.

\begin{tabular}{lll}
\hline Region & Axial Temperature (K) & $\begin{array}{l}\text { Axial Uranium } \\
\text { Density }\left(\mathbf{g} / \mathbf{c m}^{\mathbf{3}}\right)\end{array}$ \\
\hline 1 & 300 & 0.4 \\
2 & 800 & 0.6 \\
3 & 1300 & 1.0 \\
4 & 1800 & 1.0 \\
5 & 2300 & 1.0 \\
\hline
\end{tabular}

TABLE III. Energy group structure and power fraction.

\begin{tabular}{lll}
\hline $\begin{array}{l}\text { Energy } \\
\text { Group }\end{array}$ & Upper Limit $(\mathbf{e V})$ & Fraction of Power \\
\hline 1 & $1.69 \mathrm{E}+07$ & 0.0017 \\
2 & $3.68 \mathrm{E}+06$ & 0.0100 \\
3 & $8.21 \mathrm{E}+05$ & 0.0094 \\
4 & $1.11 \mathrm{E}+05$ & 0.0036 \\
5 & $3.18 \mathrm{E}+04$ & 0.0039 \\
6 & $9.12 \mathrm{E}+03$ & 0.0019 \\
7 & $5.53 \mathrm{E}+03$ & 0.0054 \\
8 & $2.04 \mathrm{E}+03$ & 0.0152 \\
9 & $4.54 \mathrm{E}+02$ & 0.0273 \\
10 & $1.01 \mathrm{E}+02$ & 0.0115 \\
11 & 22.6 & 0.0011 \\
12 & 8.32 & 0.0038 \\
13 & 1.86 & 0.0301 \\
14 & 0.7 & 0.0990 \\
15 & 0.2 & 0.7088 \\
16 & 0.015 & 0.0673 \\
\hline
\end{tabular}


Development of A Robust Tri-Carbide Fueled Reactor for Multi-megawatt Space Power and Propulsion Applications

\subsection{THERMAL HYDRAULIC AND CFD ANALYSES}

A nuclear thermal rocket engineering simulation computer code [15] with modifications is used to perform thermal fluid design analysis for the SLHC nuclear thermal rocket system [16]. A schematic diagram of the SLHC nuclear rocket engine system was shown earlier in Figure 3. The hydrogen coolant is released as a gas from the tank and goes through a turbo-pump, which increases its pressure. Then the hydrogen cools the nozzle as well as in the reflector and this pre-heated hydrogen (except for the turbine bypass fraction) is used to drive the turbine, which powers the turbo-pump [17]. Afterward the merged streams of hydrogen arrive in the core at a low temperature and a high pressure. The coolant passes through the SLHC core by way of the many square micro-channels being heated to a very high temperature. This heating increases the velocity of the gas, while decreasing pressure. The gas enters the thrust chamber at high velocity, temperature and pressure before it is exhausted through the nozzle to create thrust.

The system simulation code was originally developed for analysis of NERVA-Derivative and Pratt and Whitney XNR-2000 nuclear thermal rockets. For these analyses, the code was modified and adopted to the new SLHC geometry but with the square channels modeled as circular. In addition, the axial power profile used by the code was taken from the neutronics calculations described earlier. The model simulates a full-topping expander cycle engine system and the thermo-fluid dynamics of the core coolant/propellant (hydrogen) flow. Hydrogen properties are evaluated using the PH2 subroutine for para-hydrogen properties from data evaluated by White [18] and based originally on NASA/NIST databases [19]. The code is modular being composed of different sub-routines for the turbo-pump, nozzle, reflector, turbine, and core. Calculations are iterative requiring initial guesses for mass flow rate, pump outlet pressure, and core thermal power. A solution converges on the main parameters of the system specified by the user-namely chamber exit temperature and pressure.

In the first part, the performance of the SLHC core is evaluated to obtain the basic operating characteristics over a range of thrust levels from 44.5 to $222 \mathrm{kN}$ (10 to $50 \mathrm{klbf}$.) and for different fuel wafer thicknesses from $1 \mathrm{~mm}$ to $2 \mathrm{~mm}$. This analysis establishes the envelope of permissible operating parameters for the system and permits the optimization of the core design for a prescribed rocket performance. These analyses were conducted assuming a constant fuel thermal conductivity of $50 \mathrm{~W} / \mathrm{mK}$, a constant $30 \%$ void fraction (flow area), a nozzle area ratio of 300, and a constant chamber exit temperature of $2800 \mathrm{~K}$ and pressure of $4.83 \mathrm{MPa}(700 \mathrm{psi})$. This yields a constant Isp of $930 \mathrm{~s}$ for these analyses since the exit temperature is constant and the nozzle configuration is the same. Results of these analyses are presented in Table IV. In addition, the effect of chamber exit temperature on rocket performance and fuel temperature was evaluated over the range of $2500 \mathrm{~K}$ to $3000 \mathrm{~K}$ (see Table V).

Due to the unique square design of the coolant channels formed by the fuel, a detailed computational fluid dynamic analysis was performed on the flow distribution using FLUENT. The results were then compared to the flow distribution of a tubular coolant channel of equivalent hydraulic diameter, which is employed in the system model and 
Development of A Robust Tri-Carbide Fueled Reactor for Multi-megawatt Space Power and Propulsion Applications

code. Comparison of velocity, temperature, and pressure drop was made between the square-lattice and circular channel geometries for a range of hydraulic diameters from $0.75 \mathrm{~mm}$ to $5 \mathrm{~mm}$ and at a distance of $10 \mathrm{~cm}$ from the core inlet (see Figures 11 through $13)$.

To illustrate and perhaps explain the effect of small channel dimensions on the validity of using an equivalent hydraulic diameter, the velocity and temperature contours through the square-lattice and equivalent circular channels was calculated using the computational fluid dynamics (CFD) computer code, FLUENT. These distributions are shown in Figures 14 and 15.

As a CFD code, FLUENT solves the fundamental conservation equations for microscopic regions. It solves the Navier-Stokes equations using a finite element method on a grid generated directly in FLUENT 4.5. CFD methods, as they calculate the flow patterns and properties at every point of a detailed grid, are very accurate. Development of a model requires assumptions to match as well as possible the actual conditions in the channel. FLUENT solves the conservation equations for two or three-dimensional cases. A three dimensional grid was used to model the square channel and a two dimensional for the cylindrical channel. The symmetry of the geometries is used to minimize the mesh. In the case of the cylinder, an half axial profile of the cylinder is consider using the axial symmetry. In the case of the square channel, a quarter of the channel is modeled, using the two planar symmetries of the square geometry.

For all types of problems, as shown in the user's guide [17], FLUENT solves the conservation equations for mass, momentum, and energy (if heat transfer is involved). The "energy" option in the setup of the problem is chosen to calculate temperature distributions and heat transfer phenomenon. The flow is turbulent with Reynolds numbers in the range of about $10^{4}-10^{6}$. With various turbulence models available in FLUENT, two-equation turbulence models are the most widely used in engineering simulations. This study uses the standard $\mathrm{k}-\varepsilon$ model, which is a better alternative to the one-equation Spalart-Allmaras model [20]. A constant fuel centerline temperature of $3000 \mathrm{~K}$ was, a constant thermal conductivity of $50 \mathrm{~W} / \mathrm{mK}$, and a heat generation rate of $3000 \mathrm{MW} / \mathrm{m}^{3}$ was assumed for this analysis. The user-defined hydrogen properties of thermal conductivity, viscosity, and specific heat were supplied to FLUENT as second order polynomial curve-fits to data taken from White [15]. These were evaluated at 6.89 $\mathrm{MPa}(1000 \mathrm{psi})$, the assumed core inlet pressure for these analyses.

\subsection{Results of Thermal Hydraulic Analysis}

\subsubsection{Optimization of Core Design}

For a required thrust level the necessary core power and propellant flow rate can be seen in Table IV. These values hold regardless of wafer thickness (or related heat flux) since the void fraction is a constant (30\%) and chamber temperature and pressure and nozzle configuration are constant, which also fixes Isp in this analysis. However, for a given wafer thickness, higher heat fluxes are required for greater thrust. This relationship 
Development of A Robust Tri-Carbide Fueled Reactor for Multi-megawatt Space Power and Propulsion Applications

between wafer thickness and thermal and mechanical design limits are best shown in Tables IV through V. It is clear that to achieve a required thrust level for thicker wafers becomes difficult owing to the higher heat flux required and the concomitant increase in fuel surface temperature and fuel centerline temperature. Then for an established safety margin limiting each temperature to say $3000 \mathrm{~K}$ and $3100 \mathrm{~K}$ respectively, certain combinations of required thrust level and wafer thickness become incompatible (indicated as shaded areas in Table IV. Similar to imposed thermal limits, mechanical limitations based on allowable shear stress due to core pressure drop impose limitations on channel dimensions and hence wafer thickness. Since void fraction or flow area remains a constant $30 \%$, smaller coolant channels are the result of thinner wafers leading to greater pressure drop. Then for a given mechanical strength criteria, Table IV or similar analyses can be used to place performance limitations on certain core designs (wafer thicknesses). The combined result reveals that a thick fuel will be mechanically strong with small pressure drops, while a thin fuel will be thermally robust with less mechanical strength and more axial stress. An optimum fuel thickness will balance the thermal and mechanical strengths of the fuel. A key advantage to the SLHC concept is that it enables the design of an entire class of rockets using the same fabrication technology based on varying wafer thickness within thermal and mechanical limits.

As improvements in fuel design progress and limitations on the fuel are relaxed, a higher performing rocket can be designed as shown in Table V. If higher chamber temperatures can be sustained, higher Isp is attainable with corresponding smaller mass flow rates for a given thrust level. This is in accordance with the relationship between Isp and chamber temperature discussed in the introduction above. The resulting higher Isp allows for reduced launch costs and/or greater payloads.

\subsubsection{CFD Comparison of Square-lattice and Circular Channel Geometries}

The comparison of square-lattice and circular channel geometries over a range of equivalent diameters was made for two different core inlet velocities of 20 and $100 \mathrm{~m} / \mathrm{s}$. The average velocity, temperature, and pressure drop at a distance of $10 \mathrm{~cm}$ into the core is shown in Figures 11 through 13 for the $100 \mathrm{~m} / \mathrm{s}$ case. In each case these values have been mass flow weighted. For all parameters the greatest differences between the geometries occurs for small equivalent diameters less than $3 \mathrm{~mm}$ and is especially so for the higher inlet velocity $(100 \mathrm{~m} / \mathrm{s})$.

The velocity and temperature contours through the square-lattice and equivalent circular channels are shown in Figures 14 and 15 for channel widths of $1 \mathrm{~mm}$ and $10 \mathrm{~mm}$ at a distance of $10 \mathrm{~cm}$ from the core inlet. For both the velocity and temperature contours the gradient in the corner of the channel is less for the small channel than for the larger one. Since this gradient occurs in the boundary layer between wall and the bulk flow, the contours of the boundary layer appear different for the smaller channel. Indeed, the shape of the smaller channel contours is more rounded than square. For the smaller channel, the effects of the corner are more pronounced and the channel perimeter available for heat transfer to the bulk propellant is effectively reduced. It should be noted 
Development of A Robust Tri-Carbide Fueled Reactor for Multi-megawatt Space Power and Propulsion Applications

TABLE IV. Reactor power, mass flow rate for different thrust levels and fuel surface and centerline and core pressure drop for different wafer thicknesses.

\begin{tabular}{|c|c|c|c|c|c|c|c|c|c|c|c|c|c|c|c|c|c|}
\hline \multirow[b]{2}{*}{$\begin{array}{c}\text { Thrust } \\
(\mathrm{kN},(\mathrm{lbf}))\end{array}$} & \multirow[b]{2}{*}{$\begin{array}{c}\mathrm{P} \\
(\mathrm{MW})\end{array}$} & \multirow[b]{2}{*}{$\begin{array}{c}\dot{m} \\
(\mathrm{~kg} / \mathrm{s})\end{array}$} & \multicolumn{3}{|c|}{$1.00 \mathrm{~mm}$} & \multicolumn{3}{|c|}{$1.25 \mathrm{~mm}$} & \multicolumn{3}{|c|}{$1.5 \mathrm{~mm}$} & \multicolumn{3}{|c|}{$1.75 \mathrm{~mm}$} & \multicolumn{3}{|c|}{$2.0 \mathrm{~mm}$} \\
\hline & & & $\begin{array}{l}\text { Ts } \\
(\mathrm{K})\end{array}$ & $\begin{array}{l}\mathrm{Tcl} \\
(\mathrm{K})\end{array}$ & $\begin{array}{c}\mathrm{P} \\
(\mathrm{psi})\end{array}$ & $\begin{array}{l}\text { Ts } \\
(\mathrm{K})\end{array}$ & $\begin{array}{l}\mathrm{Tcl} \\
(\mathrm{K})\end{array}$ & $\begin{array}{c}\mathrm{P} \\
(\mathrm{psi})\end{array}$ & $\begin{array}{l}\text { Ts } \\
(\mathrm{K})\end{array}$ & $\begin{array}{l}\mathrm{Tcl} \\
(\mathrm{K})\end{array}$ & $\mathrm{P}$ (psi) & $\begin{array}{l}\text { Ts } \\
(\mathrm{K})\end{array}$ & $\begin{array}{l}\mathrm{Tcl} \\
(\mathrm{K})\end{array}$ & $\begin{array}{c}\mathrm{P} \\
\text { (psi) }\end{array}$ & $\begin{array}{c}\text { Ts } \\
(\mathrm{K})\end{array}$ & $\begin{array}{l}\mathrm{Tcl} \\
(\mathrm{K})\end{array}$ & $\mathrm{P}(\mathrm{psi})$ \\
\hline $44.5(10)$ & 209 & 4.8 & 2835 & 2840 & 17.5 & 2869 & 2876 & 17.0 & 2909 & 2923 & 13.9 & 3019 & 3043 & 11.7 & 3093 & 3131 & 10.1 \\
\hline 66.7 (15) & 313 & 7.3 & 2866 & 2872 & 44.1 & 2903 & 2917 & 34.3 & 2950 & 2974 & 28.0 & 3012 & 3048 & 23.7 & 3101 & 3160 & 20.6 \\
\hline $111(25)$ & 521 & 12.1 & 2865 & 2876 & 103.7 & 2904 & 2927 & 81.6 & 2962 & 3004 & 67.4 & 3042 & 3112 & 57.5 & 3165 & 3272 & 50.3 \\
\hline $133(30)$ & 626 & 14.5 & 2867 & 2880 & 139.7 & 2909 & 2938 & 110.6 & 2972 & 3024 & 91.7 & 3065 & 3152 & 78.6 & 3204 & 3375 & 69.0 \\
\hline $178(40)$ & 835 & 19.3 & 2872 & 2892 & 221.0 & 2920 & 2963 & 176.9 & 2995 & 3068 & 147.9 & 3107 & 3230 & 127.6 & 3284 & 3970 & 112.7 \\
\hline $222(50)$ & 1043 & 24.1 & 2878 & 2903 & 311.8 & 2933 & 2989 & 252.1 & 3016 & 3119 & 212.4 & 3150 & 3311 & 184.4 & 3369 & 4583 & 163.6 \\
\hline
\end{tabular}


Development of A Robust Tri-Carbide Fueled Reactor for Multi-megawatt Space Power and Propulsion Applications

however that this is a second order effect since on the whole there is greater total channel perimeter per assembly available for heat transfer for smaller channels owing to the constant void fraction. It is just that the heat transfer is not proportional to the increase in total surface area for small channels.

The result is that smaller channels should be modeled as slightly larger equivalent diameters which by the definition of equivalent diameter is equivalent to saying a smaller effective perimeter for heat transfer per unit flow area (effectively reduced by the corner's larger significance for smaller channels). These observations are in agreement with the earlier plots of the mass flow averaged velocity, temperature, and pressure drop shown in Figures 11 through 13. These figures illustrate for small channels of $3 \mathrm{~mm}$ or less that modeling of the square-lattice channels as circular channels is valid if a slightly larger equivalent diameter were employed. This correlation must be accounted for in future analyses of the SLHC design.

TABLE V. Specific Impulse and Mass Flow Rate for Different Chamber Temperatures

\begin{tabular}{|c|c|c|}
\hline $\begin{array}{c}\text { Chamber } \\
\text { Temperature }\end{array}$ & $\begin{array}{c}\text { Specific } \\
\text { Impulse (s) }\end{array}$ & $\begin{array}{c}\text { Mass Flow } \\
\text { Rate }(\mathrm{kg} / \mathrm{s})\end{array}$ \\
\hline \hline $2500 \mathrm{~K}$ & 864.7 & 15.51 \\
$2600 \mathrm{~K}$ & 884.4 & 15.16 \\
$2700 \mathrm{~K}$ & 905.5 & 14.80 \\
$2800 \mathrm{~K}$ & 926.5 & 14.46 \\
$2900 \mathrm{~K}$ & 948.5 & 14.12 \\
$3000 \mathrm{~K}$ & 970.4 & 13.79 \\
\hline
\end{tabular}

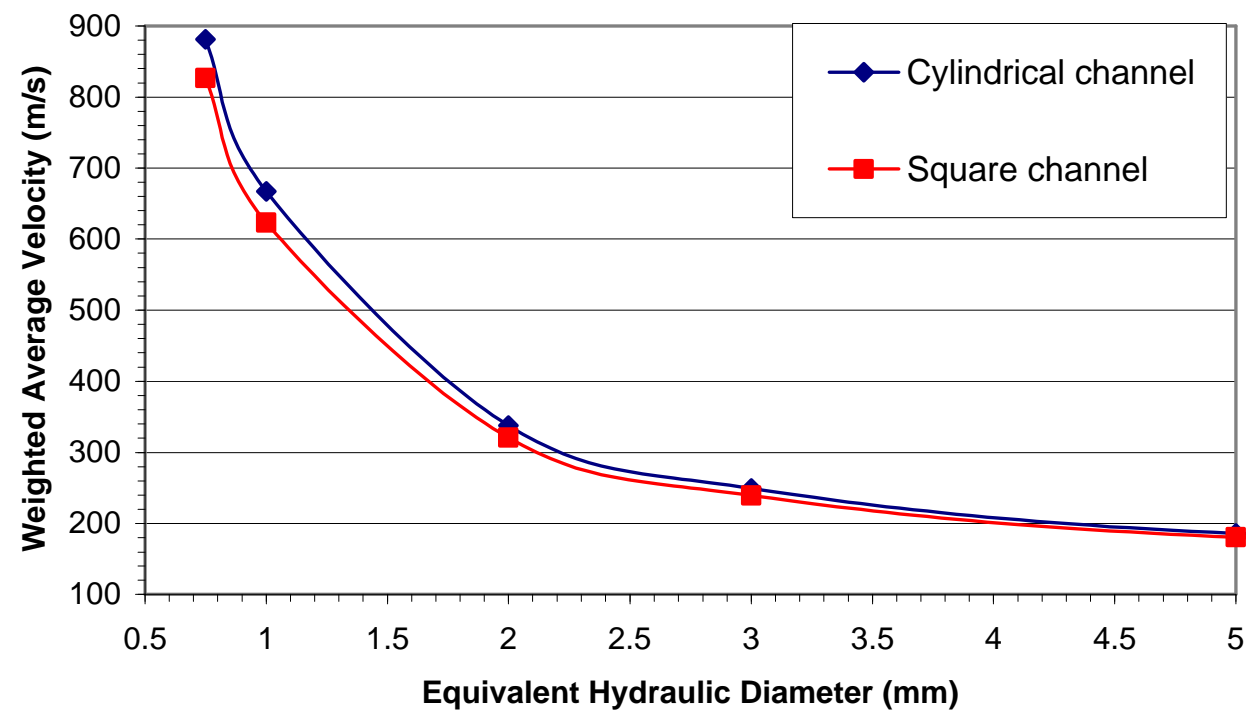

FIGURE 11 - Average outlet velocity according to different hydraulic diameters $(\mathrm{Vi}=100 \mathrm{~m} / \mathrm{s})$ 
Development of A Robust Tri-Carbide Fueled Reactor for Multi-megawatt Space Power and Propulsion Applications

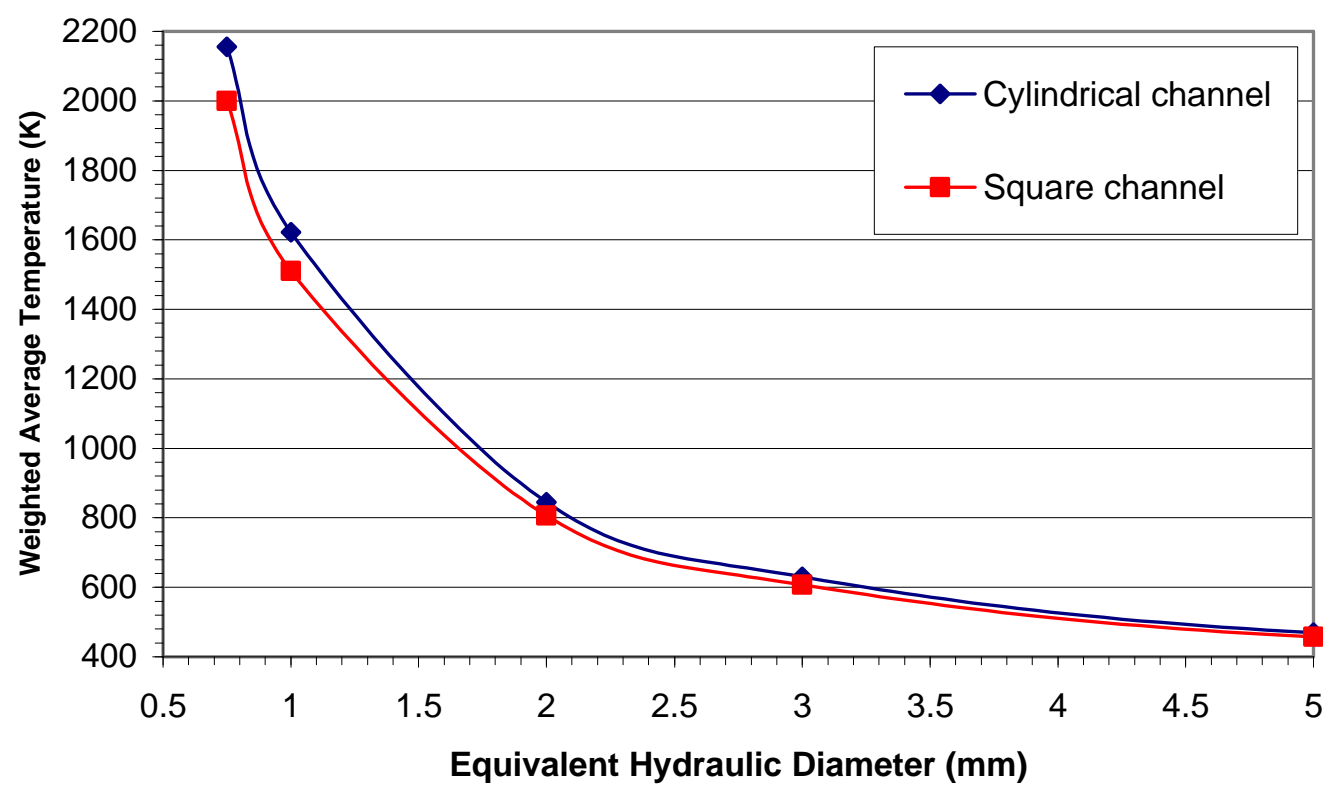

FIGURE 12 - Average outlet temperature according to different hydraulic diameters (Vi=100 m/s)

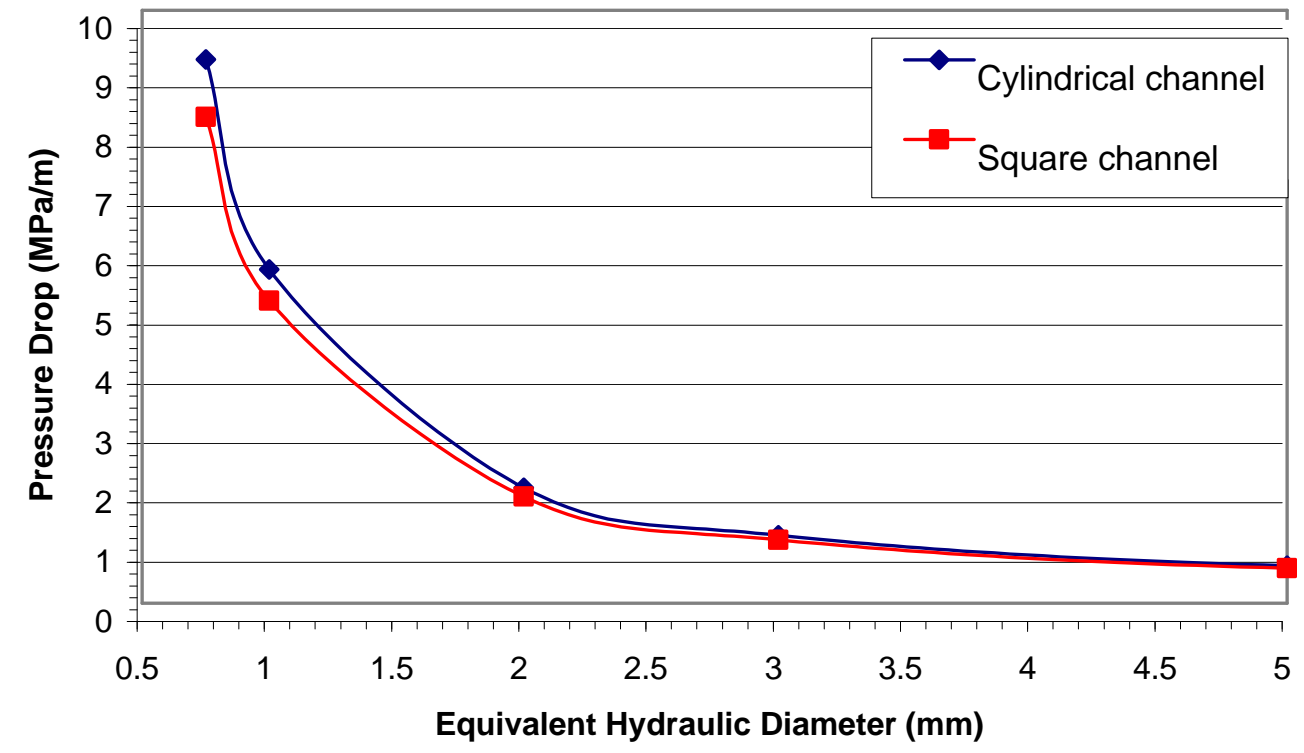

FIGURE 13 - Pressure drop according to different hydraulic diameters (Vi=100 m/s) 
Development of A Robust Tri-Carbide Fueled Reactor for Multi-megawatt Space Power and Propulsion Applications

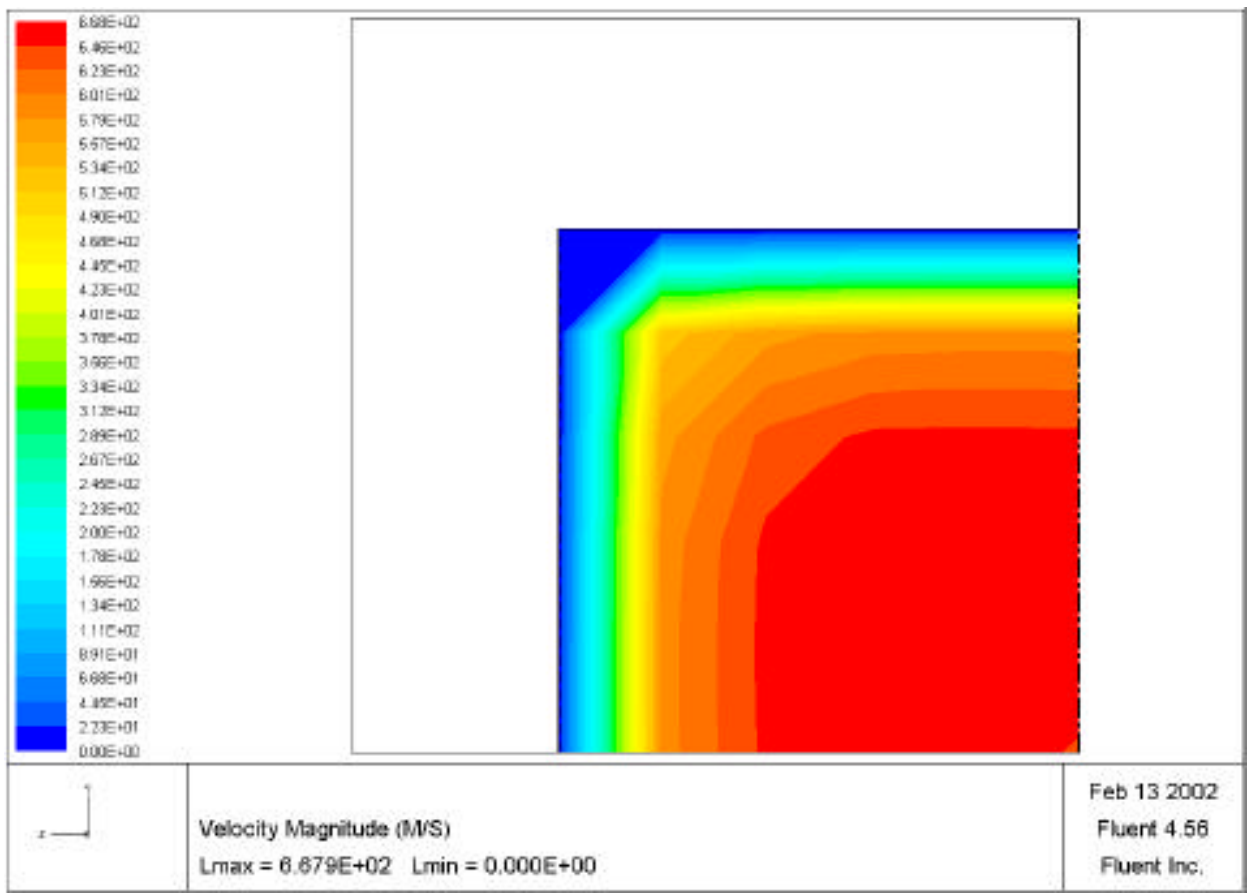

a. $1 \mathrm{~mm}$ square channel

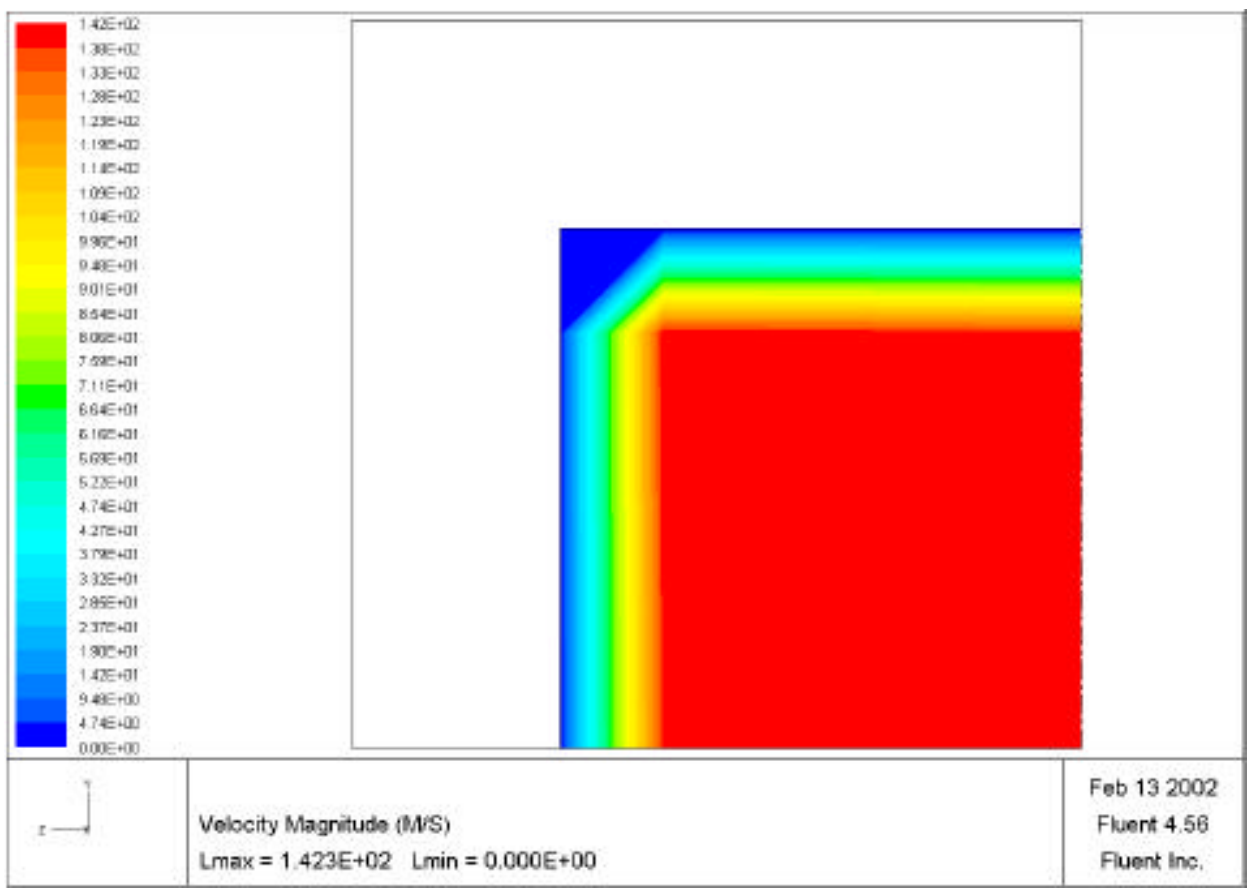

b. $10 \mathrm{~mm}$ square channel

FIGURE 14 - Velocity distribution $10 \mathrm{~cm}$ from core inlet. 
Development of A Robust Tri-Carbide Fueled Reactor for Multi-megawatt Space Power and Propulsion Applications

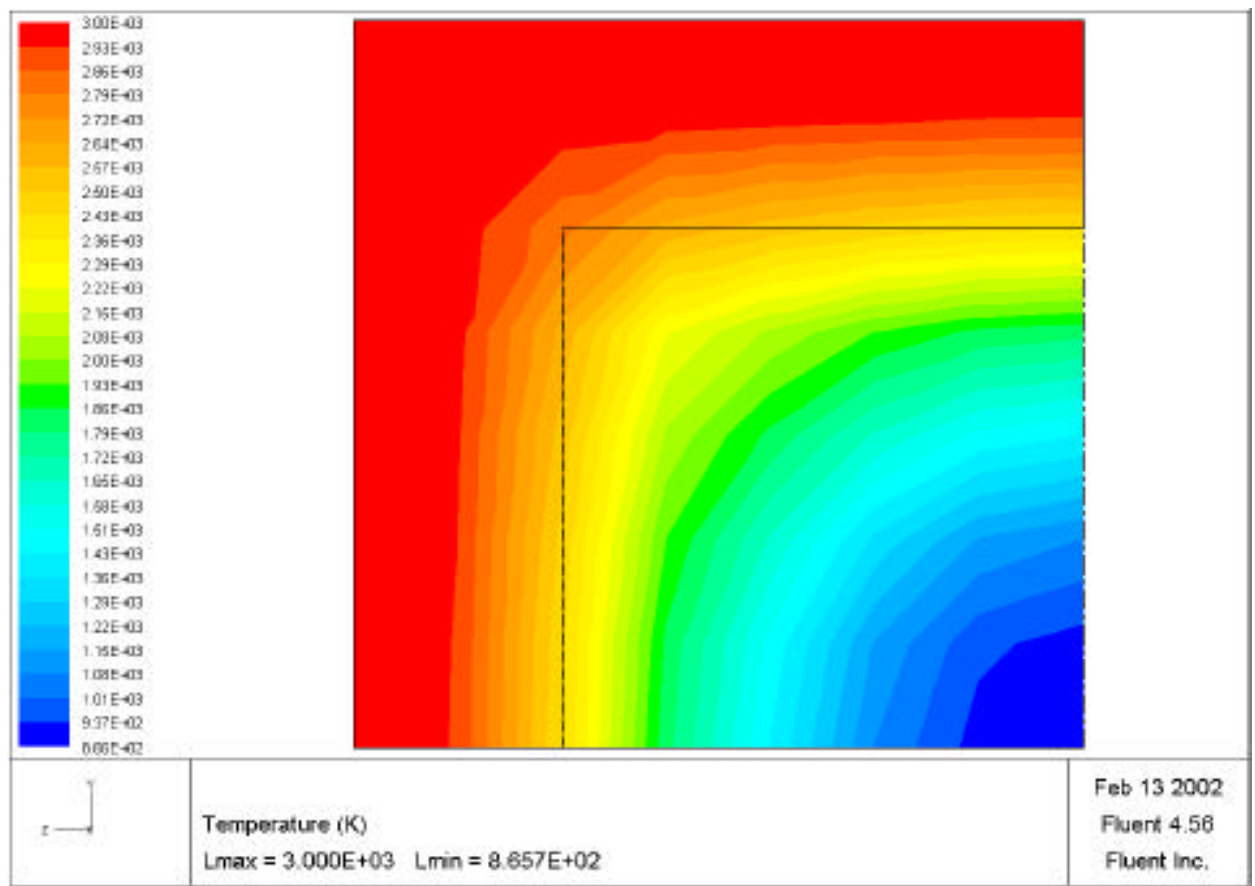

a. $1 \mathrm{~mm}$ square channel

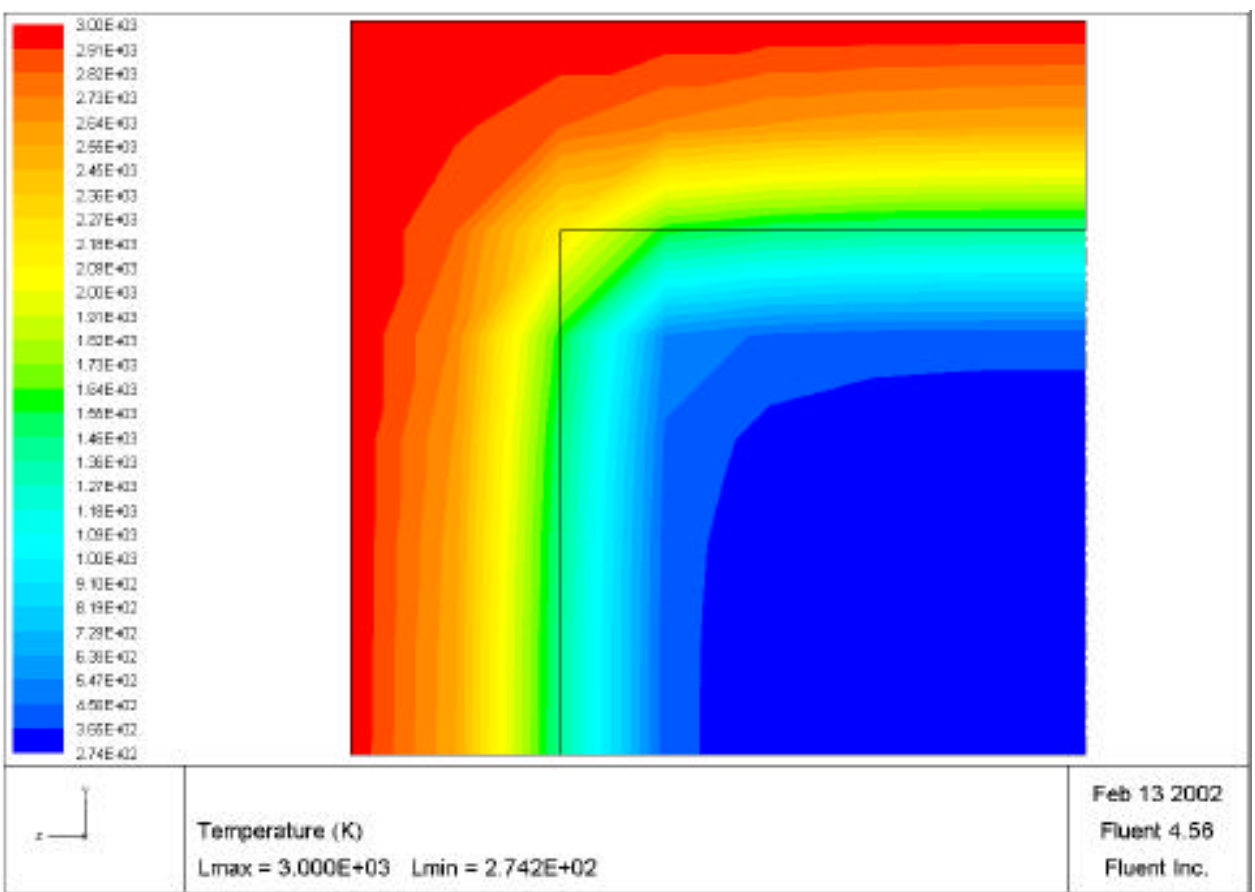

a. $10 \mathrm{~mm}$ square channel

FIGURE 15. Temperature distribution $10 \mathrm{~cm}$ from core inlet. 
Development of A Robust Tri-Carbide Fueled Reactor for Multi-megawatt Space Power and Propulsion Applications

\subsection{CONCLUSIONS}

A method of processing near fully consolidated, solid solution mixed carbides containing at least 5\% metal mole fraction uranium was developed and extended to tri-carbide fuels of $(\mathrm{U}, \mathrm{Zr}, \mathrm{Nb}) \mathrm{C}$ and $(\mathrm{U}, \mathrm{Zr}, \mathrm{Ta}) \mathrm{C}$ for application in nuclear thermal propulsion systems. This method relies on enhanced sintering achievable through liquid-phase sintering with uranium carbide at temperatures above $2800 \mathrm{~K}$. This method produces a wellconsolidated sample in a short time of a few minutes. Additional sintering at lower temperatures below $2800 \mathrm{~K}$ is still required to permit adequate solid-phase diffusion of the constituent carbides to form a homogenous, solid solution mixed carbide fuel.

Hot hydrogen testing of these fuels at temperatures above $2500 \mathrm{~K}$ indicates the improved performance of these fuels over those tested in the Rover/NERVA programs and subsequent testing. Their performance for times as long as 4 hours indicates only minimal mass losses of about $1 \%$ total.

Detailed neutronic and thermal fluid analyses were performed to establish basic design features of the SLHC nuclear thermal rocket systems. Results of the analysis indicate that a compact nuclear engine can be designed based on tri-carbide SLHC fuel with an Isp of 930 with flexibility for thrust levels ranging from approximately 50 to $250 \mathrm{kN}$. This leads to the ability to design an entire class of rockets based on the same fabrication technology with varying wafer thickness. Optimization of rocket performance within thermal and mechanical limits is thus achieved by designing around the optimal wafer thickness. 
Development of A Robust Tri-Carbide Fueled Reactor for Multi-megawatt Space Power and Propulsion Applications

\subsection{REFERENCES}

1. R. G. JAHN, Physics of Electric Propulsion, McGraw-Hill Book Company, New York, (1968).

2. P. J. RING, E.D. Sayre, M. Van Dyke, and M. Houts, "Progress in Hardware Development for the SAFE Heatpipe Reactor System," STAIF, (2002).

3. S. BOROWSKI, L. Dudzinski, and M. McGuire, "Bimodal Nuclear Thermal Rocket (NTR) Propulsion for Power-Rich," Artificial Gravity Human Exploration Missions to Mars 52 $2^{\text {nd }}$ International Astronautical Congress 1-5, IAA-01-IAA.13.3.05, Toulouse, France, (2001).

4. J. A. ANGELO Jr. and D. Buden, Space Nuclear Power, Orbit Book Company, Malabar, (1985).

5. R. M. EISBERG and L. S. Lerner, Physics: Foundations and Applications, McGrawHill Book Company, New York, (1981).

6. L. L. LYON, "Performance of (U, Zr)C-Graphite (Composite) and of (U, Zr)C (Carbide) Fuel Elements in the Nuclear Furnace 1 Test Reactor," LA-5398-MS, Los Alamos National Laboratory, (1973).

7. D. G. CZECHOWICZ, F. G. Hampel, and E. K. Storms, "M. S. El-Genk, $8^{\text {th }}$ Symposium On Space Nuclear Power and Propulsion," AIP Conference Proceedings, vol. 910116, 1059-1063, Am. Inst. of Phys., New York, U.S.A., (1991).

8. S. ANGHAIE and N.J. Diaz, "Testing and assessment of Ternary Uranium Carbides and Uranium-Zirconium Carbonitride Based Twisted Ribbon and Cermet fuels for Space Power and Propulsion Applications," NASA-GRC Contract Report, NAS26314, (1997).

9. T. W. KNIGHT and S. Anghaie, "Processing and Fabrication of Mixed Uranium/Refractory Metal Carbide Fuels with Liquid-Phase Sintering" Journal of Nuclear Materials, 306, pp. 54-60 (2002).

10. E. STORMS, "The Behavior of $\mathrm{ZrC}_{1-\mathrm{x}}$ and $\mathrm{U}_{\mathrm{y}} \mathrm{Zr}_{1-\mathrm{y}} \mathrm{C}_{1-\mathrm{x}}$ in Flowing Hydrogen at Very High Temperatures," LA-12043-MS,UC-504 and UC- 528, Los Alamos National Laboratories, Los Alamos, (1992).

11. J.S. HENDRICKS, MCNP4B, Monte Carlo N-Particle Transport Code System Manual. RSICC Computer Code Collection, Los Alamos National Laboratories, Los Alamos, (1997).

12. R. R. GOUW, Nuclear design analysis of square-lattice honeycomb space nuclear rocket engine, Thesis: University of Florida, (2000). 
Development of A Robust Tri-Carbide Fueled Reactor for Multi-megawatt Space Power and Propulsion Applications

13. R.A. GRIMESEY, D.W. Nigg, and R.L. Curtis, COMBINE/PC-A Portable ENDF/B Version 5 Neutron Spectrum and Cross-Section Generation Program. RSICC Peripheral Shielding Routine Collection, EG\&G Idaho, Inc., Idaho Falls, (1990).

14. A. SHAPIRO, H.C. Huria, and K.W. Cho, VENTURE/PC Manual A Multidimensional Multigroup Neutron Diffusion Code System Version 2. RSICC Computer Code Collection, EG\&G Idaho, Inc., Idaho Falls, (1990).

15. J.A. GIVEN and S. Anghaie, "A Computational Model for Thermal Fluid Design Analysis of Nuclear Thermal Rockets," Nuclear Technology, 117, 87-108, (1997).

16. J. PLANCHER, Thermal and fluid design analysis of a square lattice honeycomb nuclear rocket engine, Thesis: University of Florida, (2002).

17. E. M. FURMAN, Thermal hydraulic design analysis of ternary carbide fueled square-lattice honeycomb nuclear rocket engine, Thesis: University of Florida, (1999).

18. J. G. WHITE, Development of a para- and dissociated hydrogen properties packages, Thesis: The University of Florida, (1993).

19. J. T. WALTON, Computer program for thermal and transport properties of parahydrogen from 20 to $10000 \mathrm{~K}$, NASA Technical Paper; 3378, (1993).

20. FLUENT Inc., FLUENT 4.5 User's Guide, Fluent Inc., Lebanon, (2000). 